\title{
When is a subsea anchor required for a short pipeline/SCR system?
}

\author{
Ahmed Reda ${ }^{1}$, Kristoffer K. McKee ${ }^{1}$, Ian M. Howard ${ }^{1}$ and Ibrahim A. Sultan ${ }^{2}$ \\ 1-Department of Mechanical Engineering, Curtin University, WA, Perth, Australia. \\ 2-School of Science, Engineering and Information Technology, Federation University, Australia.
}

\section{Abstract}

Connection of floating production vessels to subsea pipelines requires careful consideration of the stresses placed on the steel catenary riser (SCR), subsea spool and pipeline end termination (PLET). Due to vessel motion, environmental conditions, flow conditions and pipeline temperature gradients during start-up/shut-down and operation, the forces on all sections of the subsea pipeline system may deviate from their static configurations. Pipeline risers, PLETs and spools have design limits that must not be exceeded in order to ensure the integrity of the pipeline/SCR system. The operational/dynamic loads on the pipeline/SCR system cause expansion and contraction of the pipeline at the riser and free end locations, and these also need to be kept within the pipeline system design limits. The most appropriate method to account for the pipeline system movement is to ensure the pipeline has sufficiently long run-out to accommodate the pipeline system loading or to provide anchoring locations for the pipeline section. This paper addresses, with examples and calculations, the criteria that must be considered during the design of the pipeline/SCR system to determine if hold-back anchors are needed and their optimum locations in the system. The criteria for the anchoring are valid for short pipelines with route bend and no lateral buckling.

Keyword: Pipeline Walking, Lateral Ratcheting, Steel Catenary Riser (SCR), Thermal expansion, Subsea Anchoring System.

\subsection{Introduction}

A subsea pipeline, laid on the seabed, operated at elevated temperatures and pressures inevitably undergoes expansion [1-8]. The straining actions associated with this phenomenon must be determined during design. Tie-in spool-piece arrangement can accommodate pipeline expansion and maintain the stresses experienced by the connecting shallow water rigid riser or subsea assembly within allowable limits.

With respect to the steel catenary riser (SCR), the effects of the motion of the floating production vessel due to the environmental effects and thermal loads resulting from the pipeline expansion could lead to slippage of the mean position of the touchdown point towards the vessel [1]. Expansion towards the SCR should be kept within the allowable maximum axial displacement limit specified by the SCR design. Excessive movement of the touchdown point could result in reducing the static tension in the SCR and changing the curvature in the sag-bend region (i.e. jeopardising the integrity of the SCR). Furthermore, [1\&6] indicated that over several heat-up and cool down cycles, pipeline walking towards the SCR could result in both overstressing the spool and reducing the SCR tension.

Recent work [1] provided design criterion that could be adopted for the selection of the optimum anchor location in the presence of SCR motion, thermal transients as well as seabed inclination. However, the cited criterion is (OR USE PLURAL FOR ALL HERE) applicable to straight, short pipelines that do not undergo lateral buckling. Axial walking occurs when the pipeline moves incrementally 
overtime. This can result in progressive movement towards the SCR, downhill or towards the cooler end of the pipeline.

[1\& 7] indicated that pipeline walking causes gradual axial displacement of the entire pipeline towards one end, due to the repeated start-up and shut-down pressure and temperature cycles. The accumulated axial displacement over time can eventually lead to overloading of the spool piece or jumper.

For a short pipeline connected to the SCR, the on-bottom SCR tension was shown to dominate the walking behaviour over both the thermal transient effects and seabed sloping [1]. The expansion towards the SCR should be controlled, as this could result in shifting the touchdown point [1], which can eventually reduce the static tension in the SCR and change the curvature in the sag-bend region. This can be explained using Figure 1, which illustrates how the pipeline can walk towards the SCR as the touchdown point shifts towards the floating production vessel. The figure also illustrates how the spool between the PLET (Pipeline End Termination) and the manifold stretches gradually over time as the pipeline walks towards the SCR. Consequently, this gradual stretch could result in spool failure if not controlled or eliminated.

This paper presents the criteria and design approach that must be considered to determine the requirements for the hold-back anchors needed for the design of the pipeline/SCR system to successfully mitigate the risk above. The criteria and requirements for anchoring are valid for the combined conditions of a short pipeline, route bend and no lateral buckling.

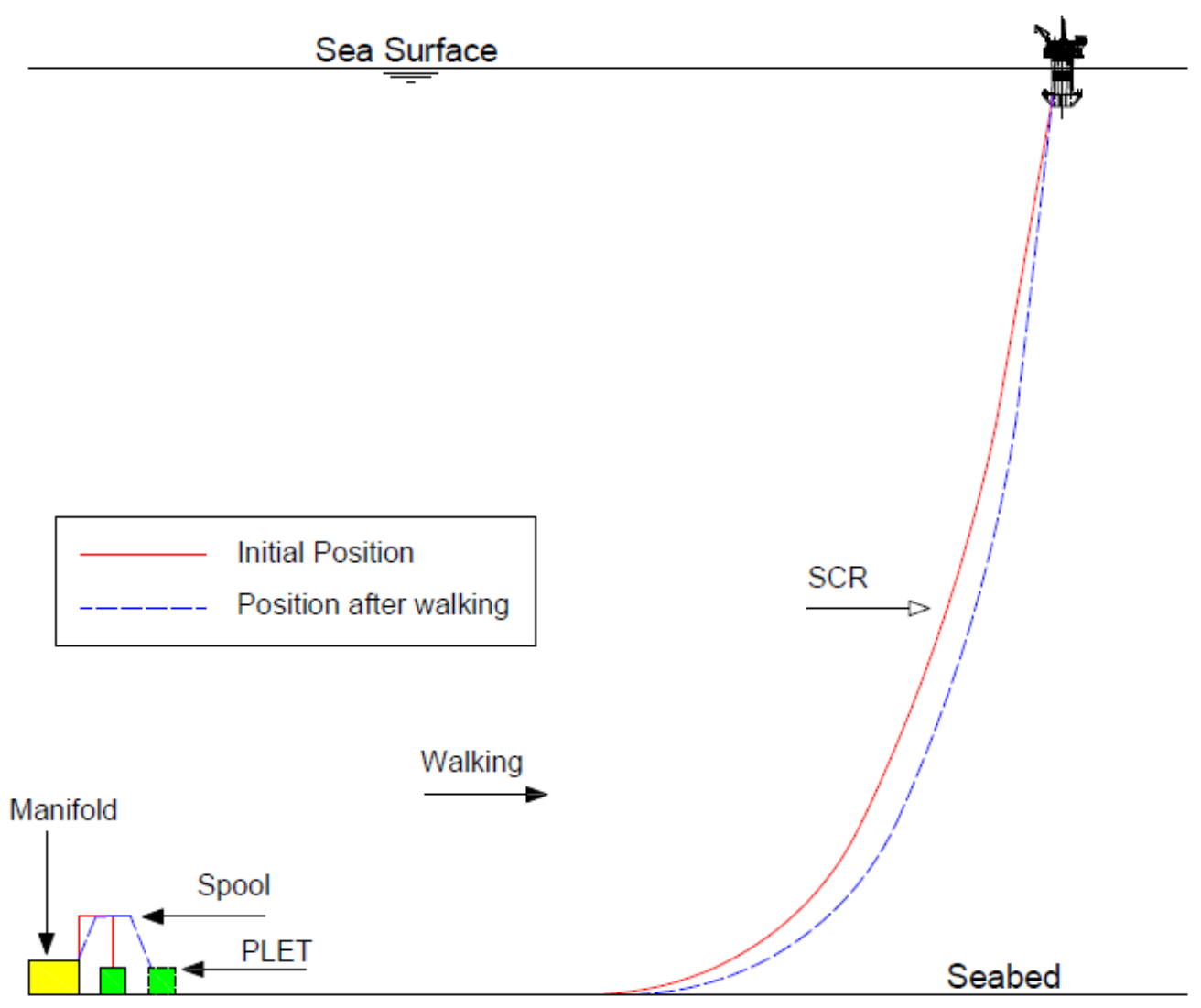

Figure 1: Schematic of pipeline walking towards SC 
During the design stages, it is important to determine the requirements of anchoring to arrest the axial walking in order to guarantee that the integrity of the tie-in spool between the PLET and manifold are not compromised. Excessive SCR tension associated with the storm conditions may result in route curve pullout, which could lead to significant implications on the field layout.

The assessments undertaken in this paper are based on results obtained from finite element simulations. The finite element model developed is validated against an analytical solution. The study undertaken here identifies the key parameters that affect pipeline axial /lateral ratcheting for a given short pipeline connected to a SCR.

The paper explains the mechanics of the pipeline expansion. It also describes the developments of the analytical solution used to validate the results from the finite element analysis. The potential methods available to anchor the pipeline and limit the axial feed-in towards the SCR are discussed.

\subsection{Steel Catenary Riser}

As indicated by [1], a floating production vessel on which the SCR is supported will be subject to excursions that are caused by environmental loads and influenced by the mooring system and other risers. Horizontal movement of the floating production vessel causes changes in the riser catenary configuration, which necessitate proper analysis for the riser in near, mean and far conditions, as shown in Figure 2.

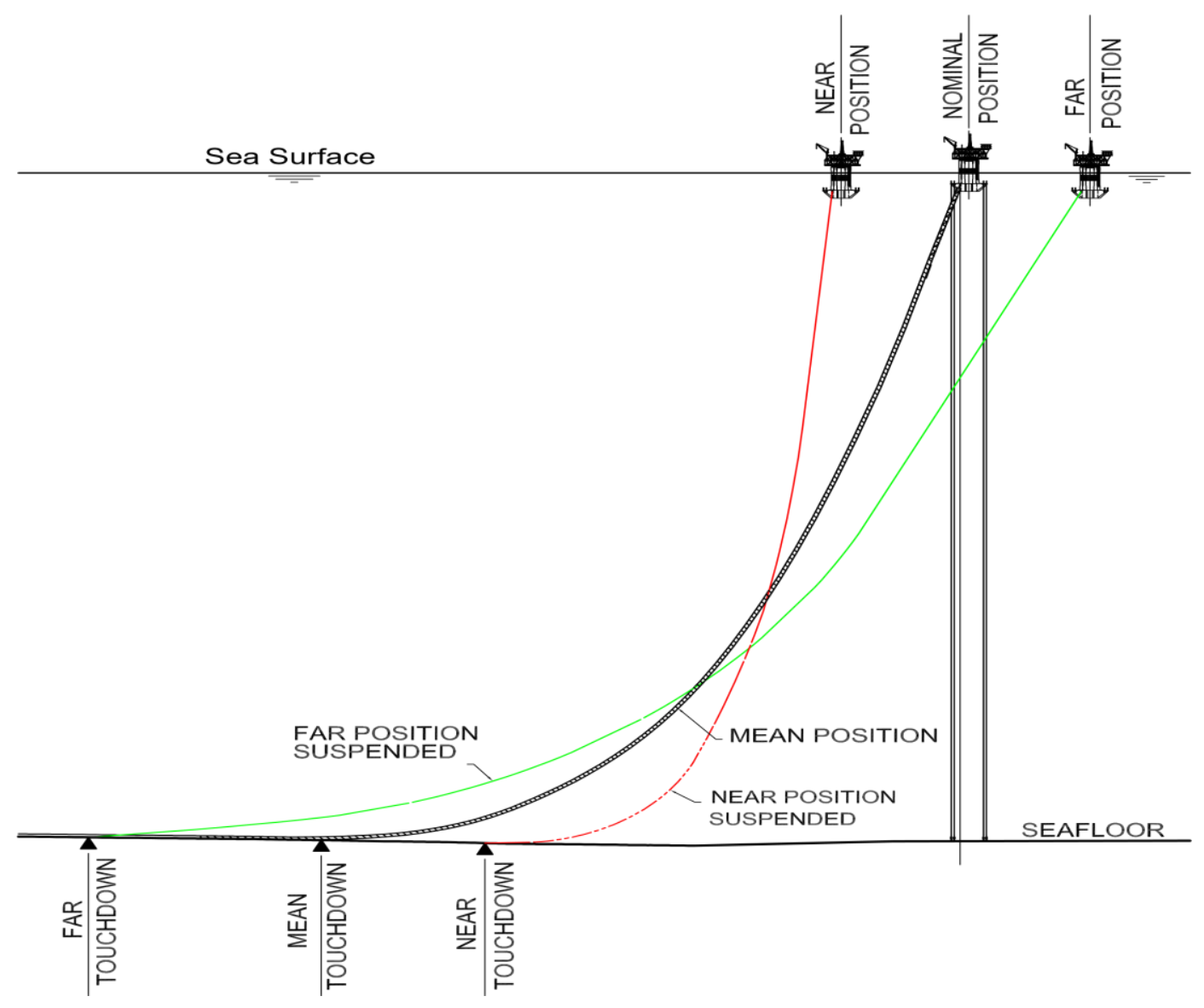




\subsection{Validation and Sensitivity Analyses}

This section presents the analyses undertaken to validate the results of the FE modelling against the analytical solutions presented in section 3.1.

In addition to the validation undertaken on the FE, sensitivity studies are undertaken to ensure the $\mathrm{FE}$ model behaves consistently.

\subsection{Derivation of Force Response}

For a short pipeline, the effective axial force is governed by seabed friction. The effective force profile during loading and unloading is shown in Figure 3.

At the end of the pipeline, the effective axial force is equal to the reaction provided by the end condition.

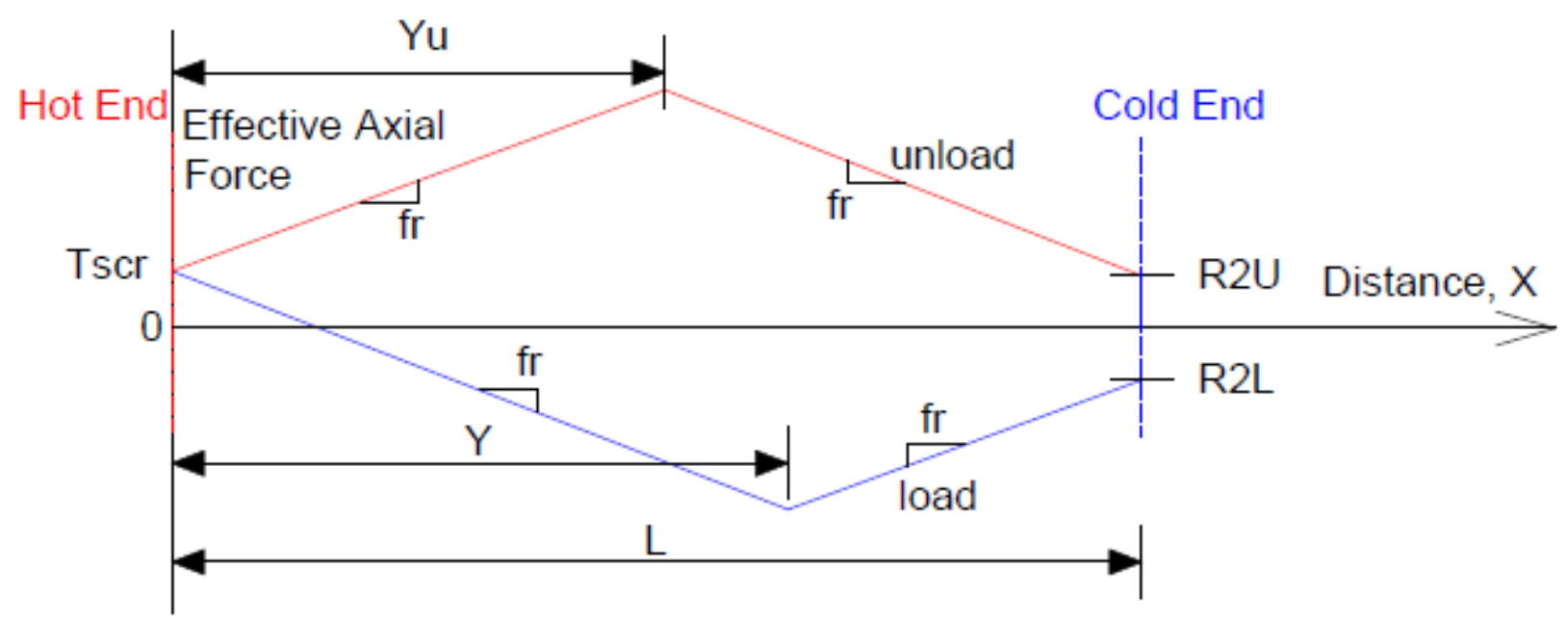

Figure 3: Effective axial force profile during Load/Unload conditions

In the example illustrated in Figure 3, the hot end is connected to a steel catenary riser with a static tension Tscr, whereas the cold end is connected to a spool with an end reaction R2L.

During the loading condition, the effective axial force in the pipeline, is calculated at the state of equilibrium using Equation 1:

$S_{\text {eff }}= \begin{cases}T s c r-f r \cdot x & x \leq Y \\ -R 2 L-f r \cdot(L-x) & x>Y\end{cases}$

where $T s c r$ and $R 2 L$ are the SCR tension and the spool reaction during loading, respectively; $f r$ is the axial pipe soil resistance. The location of the virtual anchor point $(\mathrm{Y})$ can be determined by Equation 2:

$Y=\frac{L}{2}+\frac{T s c r-R 1 L}{2 \cdot f r}$ 
For the unloading conditions, the effective axial force is determined using Equation 3 :

$S_{\text {eff }}= \begin{cases}T s c r+f r \cdot x & x \leq Y u \\ R 2 U+f r \cdot(L-x) & x>Y u\end{cases}$

where $R 2 U$ is the spool reaction during unloading.

The location of the virtual anchor point during unloading can be determined by Equation 4:

$Y u=\frac{L}{2}+\frac{T s c r-R 1 U}{2 \cdot f r}$

\subsection{Pipeline Elastic Route Stability}

Consider a curved element of a pipeline on the seabed subject to the bottom tension experienced during pipelay.

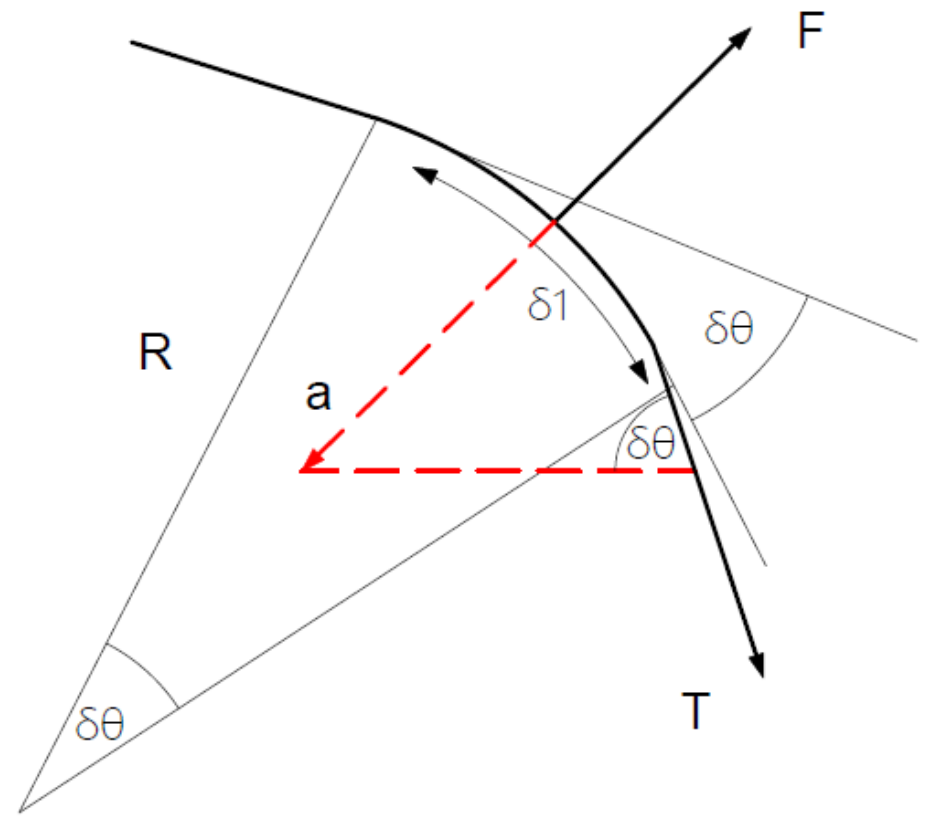

Figure 4: Force Balance on a Curved Pipeline Element

The component of the tension force normal to the pipeline (a) is counteracted by the lateral friction mobilised (F).

The frictional force is given by:

$F=\mu \cdot W_{S} . \delta l$ 
Resolve the tension ( $T$ ) to find the component normal to the pipeline (a):

$a=T \cdot \tan \delta \theta$

For stability: $\mathrm{F}>\mathrm{a}$

$\mu . W_{S} . \delta l>T \cdot \tan \delta \theta$

$\tan \delta \theta \approx \frac{\delta l}{R}$

$\mu \cdot W_{S} . \delta l>T \cdot \frac{\delta l}{R}$

Therefore, the radius of curvature $R$ should exceed the value given by Equation 10:

$R>\frac{T}{\mu \cdot W_{S}}$

where:

F: Frictional Force.

$W_{s}$ : Submerged Weight of the Pipeline per Unit Length.

$\mu$ : Coefficient of Lateral Friction.

T: Pipeline Bottom Tension.

A: Component of Tension Force Normal to the Pipeline.

$\delta \theta$ : Angle.

R: Radius of Curvature.

$l$ : Length the Pipeline element.

\subsection{Finite element modelling}

This section describes how the finite element package ABAQUS [9Error! Reference source not found.] was used to for the simulation and numerical analysis presented in this paper. The parameters used in each finite element simulation are presented in Table 1.

The following section lists the assumptions implemented in the finite element modelling:

1- The pipeline is modelled using ABAQUS PIPE31H element. An element length of $1 \mathrm{~m}$ is employed in the model; this has been found to be sufficient to accurately model the walking behaviour. 
2- The interaction between the pipe elements and the seabed is modelled as a soft, frictional contact, with decoupled axial and lateral friction. The frictional contact response is modelled in the FE analyses using a user defined subroutine that implements the non-linear monotonic response.

3- The pipe-soil interaction in the axial/lateral directions is defined using a bilinear model as illustrated in Figure 5, with a constant friction factor once the mobilization displacement is reached.

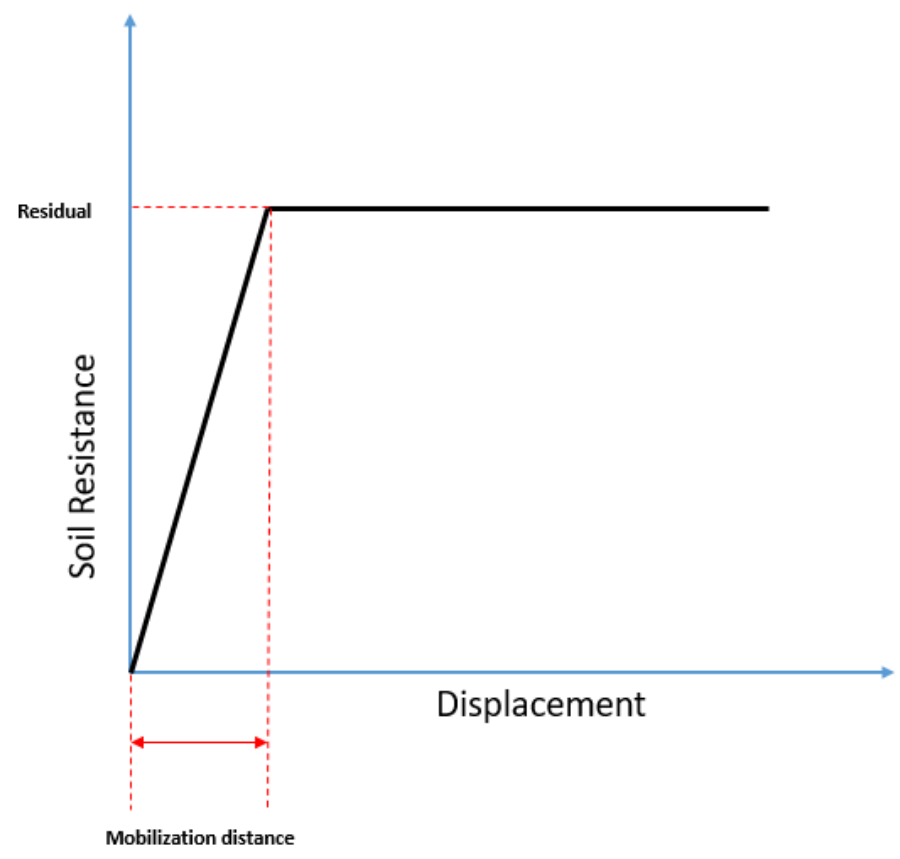

Figure 5: Bilinear model

4- The hot end of the pipeline is connected to the SCR, whereas the cold end is connected to the PLET.

5- In some cases as per Table 1 , the pipeline is modelled as a straight segment, with no route bend/curve and with a global seabed slope of 2 degrees, as per Figure 6 . The same figure highlights that the seabed is running down to the PLET. It also shows that the seabed slope is modelled by adjusting the gravity vectors into the direction shown in the figure.

6- In some cases as per Table 1, thermal transients are modelled by applying start up and shut-down pressures and temperatures as shown in Figure 7.

7- The reaction of the PLET is ignored.

8- The finite element analyses undertaken are for static conditions. 

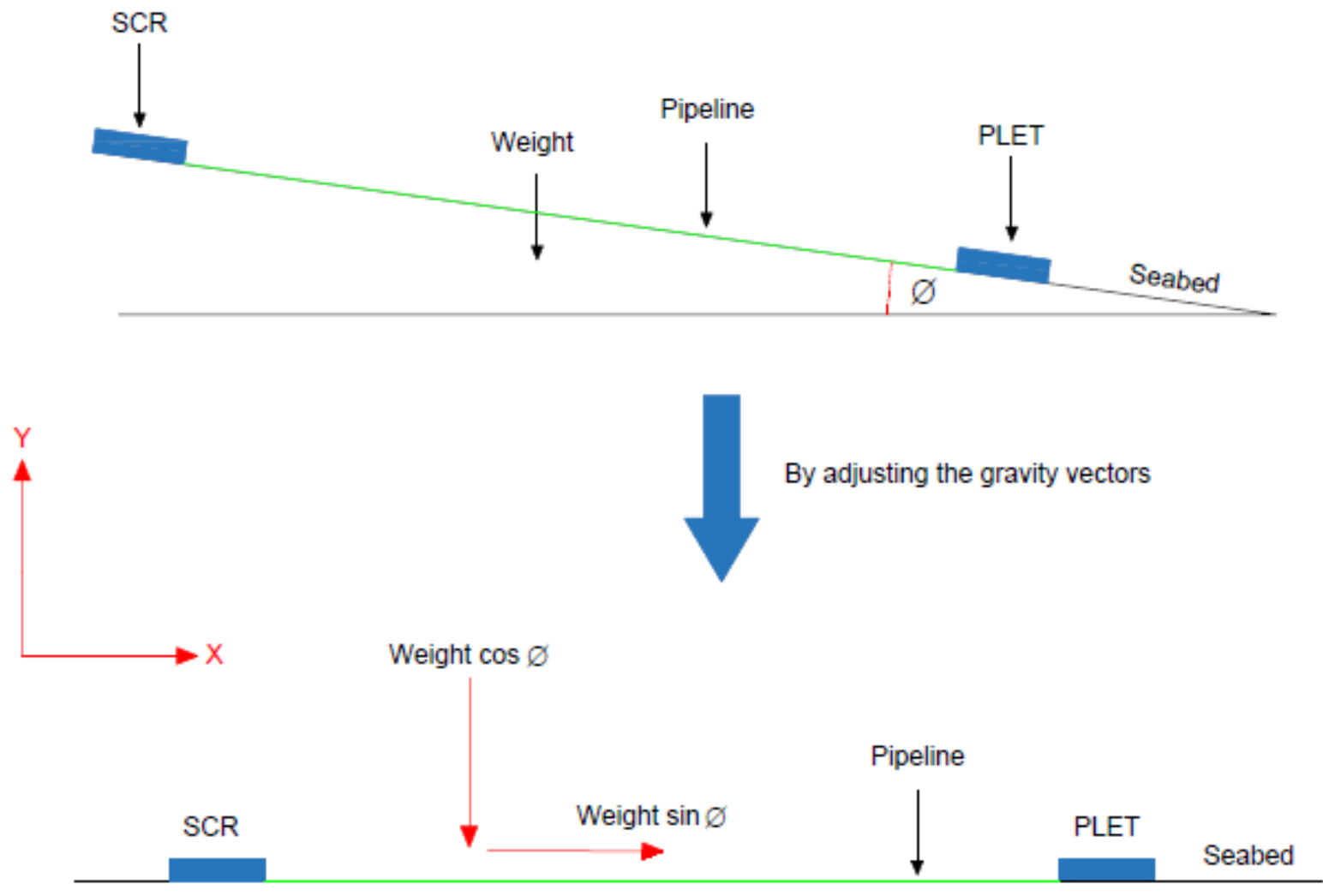

Figure 6: Seabed Slope along the Pipeline

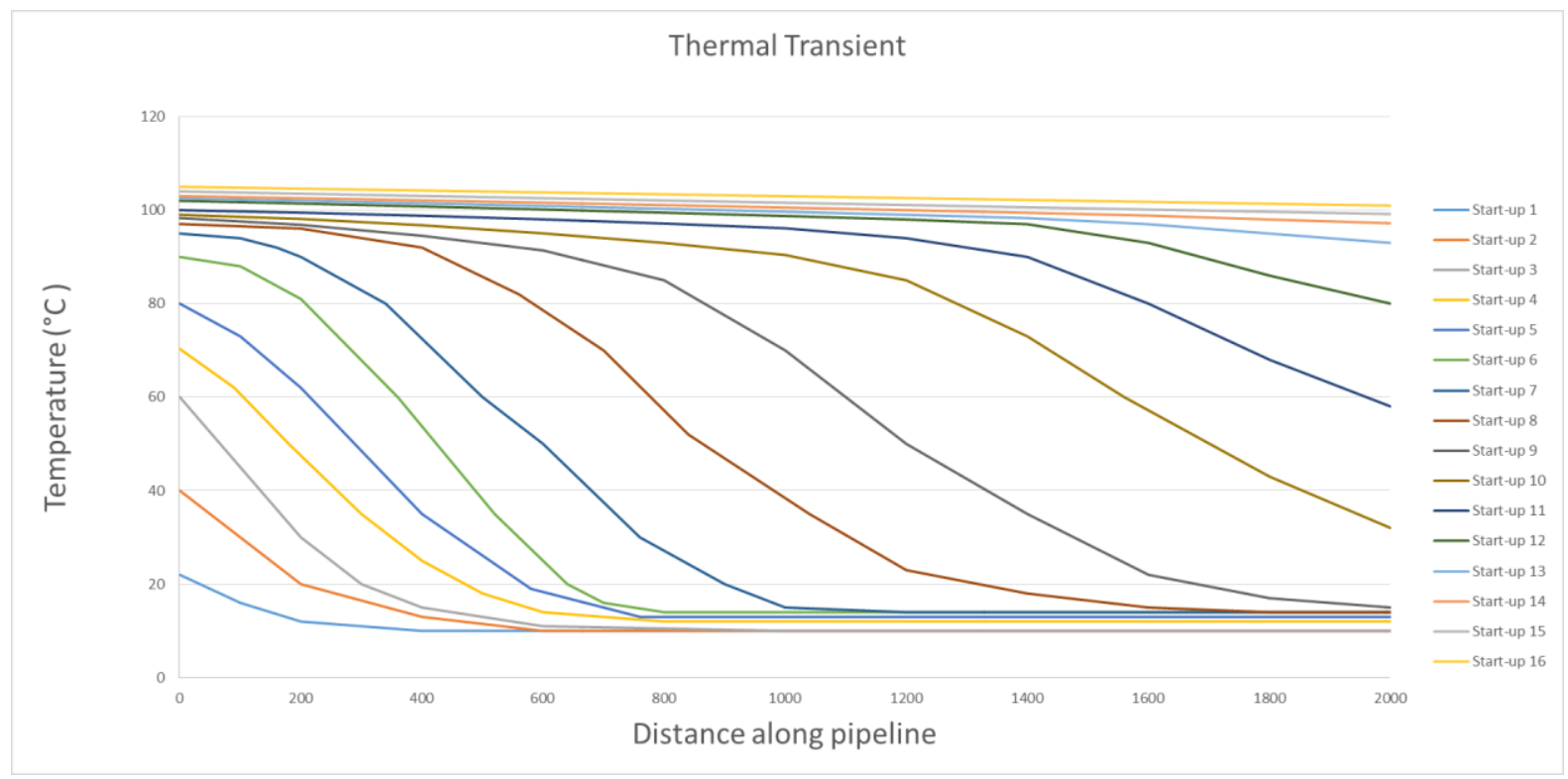

Figure 7: Full Operating Thermal Cycles 


\begin{tabular}{|c|c|c|c|c|c|c|}
\hline & 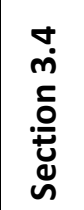 & 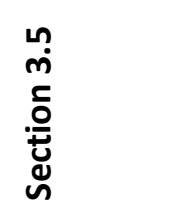 & 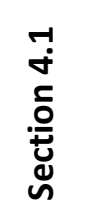 & 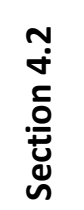 & 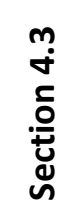 & 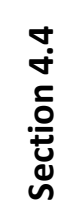 \\
\hline Seabed Considered & Flat & Flat & Flat & Flat & Flat & Flat \\
\hline Global Slope & No & $\begin{array}{l}2 \text { degrees } \\
\text { slope }\end{array}$ & No & No & No & No \\
\hline Transient considered & No & Yes & No & No & Yes & Yes \\
\hline Straight pipe & Yes & Yes & Yes & No & No & Yes \\
\hline Route curve & No & No & No & Yes & Yes & No \\
\hline
\end{tabular}

\subsection{Comparison between the Theoretical Solution and Finite element modelling}

\section{Effective Axial Force during Normal Operation}

The finite element model used in this section is presented in Figure 8. The hosting vessel is connected to the pipeline via the SCR. In this example, the seabed is modelled as a flat surface.

The pipeline is $2 \mathrm{~km}$ long. It is assumed to be straight, with no route bend/curve. The hot end is the end connected to the hosting vessel via a SCR and the cold end is free/PLET. YOU SAID IT ABOVE, CUT.

Hosting

Vessel

\section{Free End}

Pipeline

Figure 8: Model used in this section

In this section, the effective axial force profile and displacement determined from the finite element modelling is compared against the analytical solution presented in Section 3.1.

Figure 9a shows the numerical (FE) and analytical predictions of the axial displacement distribution along the pipeline segment. An excellent agreement between the two methods can be observed. Note that Points ( $A$ and $B$ ) refer to the virtual anchor points. Both finite element and the analytical solutions show that the pipeline is under the effect of the SCR tension between the SCR (Distance $=0 \mathrm{~m}$ ) and point (C). The force distribution, shown in Figure 9 b), is associated with expansion from point (B), towards the SCR and expansion from point (B) towards the PLET/free end. 
To validate the finite element modelling, the effective axial force at the cold end was checked. As can be seen from Figure $9 b$, both finite element and analytical solutions predict a net zero effective axial force at the free end. The effective axial force profile is dependent on the axial friction coefficient and the value of the SCR tension. Note that the anchor point $(A)$ is not located at the centre of the pipeline. In fact, point $(A)$ is located after the mid length of the pipeline towards the free end. This is in part due to the presence of the SCR tension.

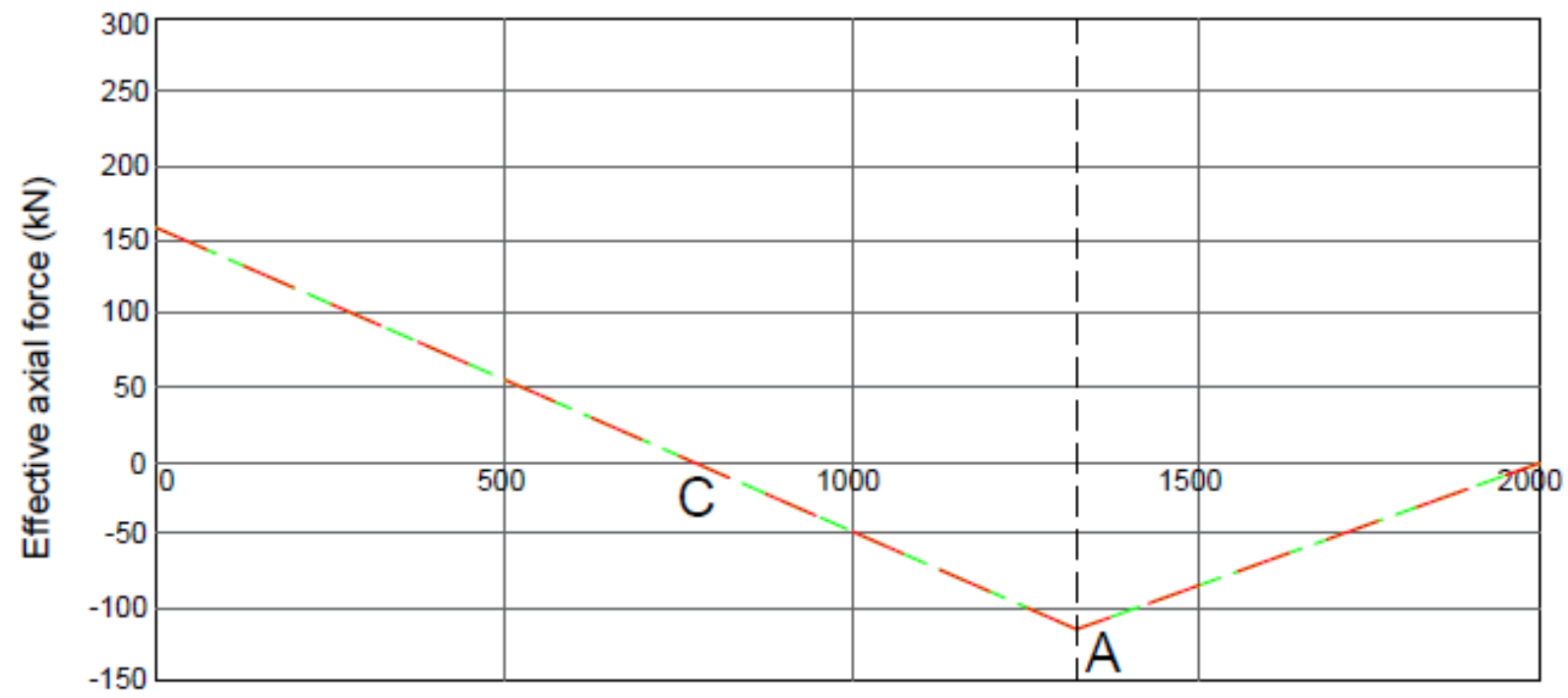

Distance along Pipeline $(\mathrm{m})$

- $\quad$ - Operating + Static SCR Tension (FE) _ _ - Operating + Static SCR Tension (Analytical)

Figure 9 a): Effective axial force profile along the pipeline

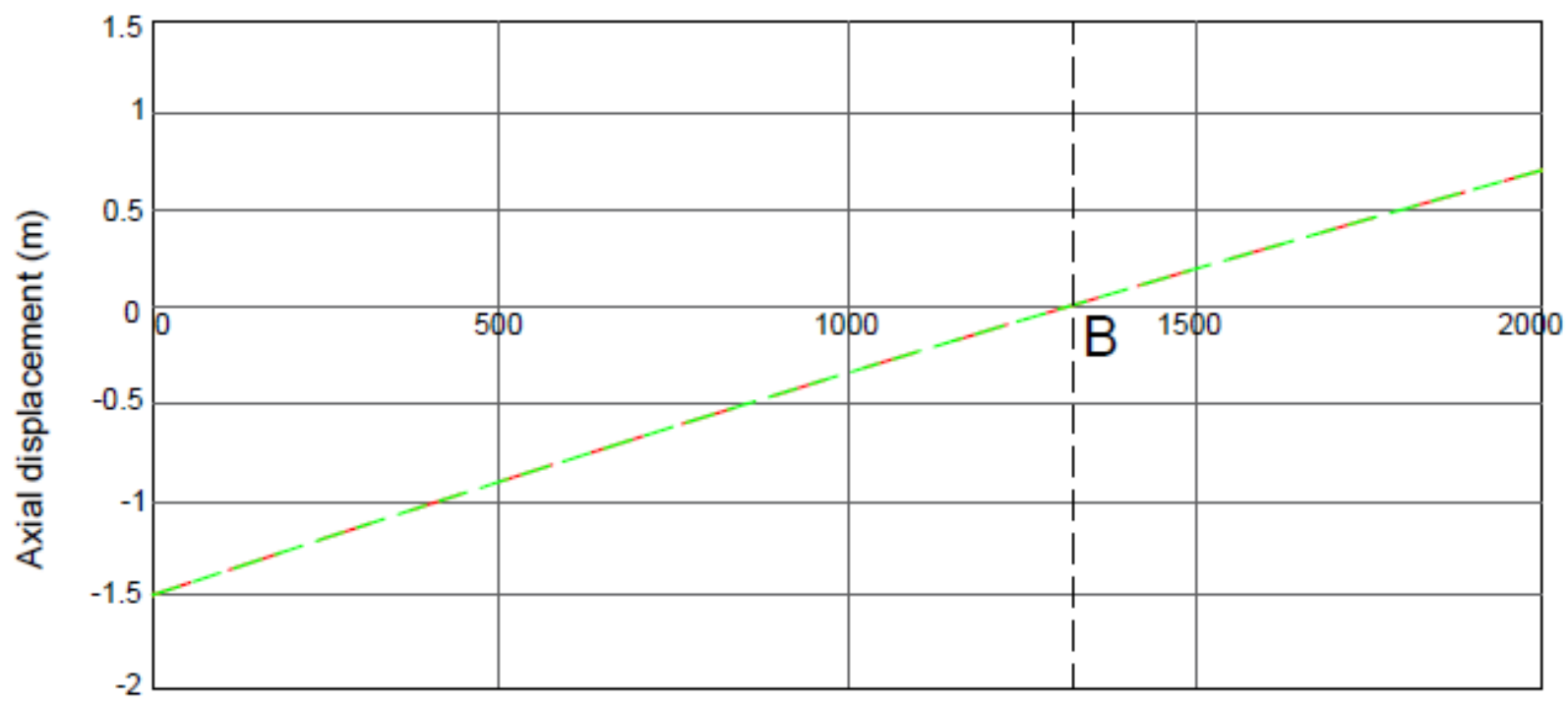

Distance along Pipeline $(\mathrm{m})$

- $\quad$ - Operating + Static SCR Tension (FE) _ _ _ Operating + Static SCR Tension (Analytical) 


\section{Effective Axial Force during Normal Operation and Unloading: No Anchor}

To validate the effective axial force during both loading and unloading scenarios, the finite element model presented in Figure 8 above was used, and the results are depicted in Figure 11. Excellent agreement between the finite element model and the analytical solution is evident from the figure.

Figure 10 also shows that during operation, the anchor point $(A)$ moves away from the SCR/hot end, and this behaviour reverses for the anchor point (B) during unloading. Eventually Points $A$ and $B$ moves away from the middle of the pipeline due to the action of the SCR tension force (i.e. asymmetrical load profile) and the asymmetric boundary conditions.

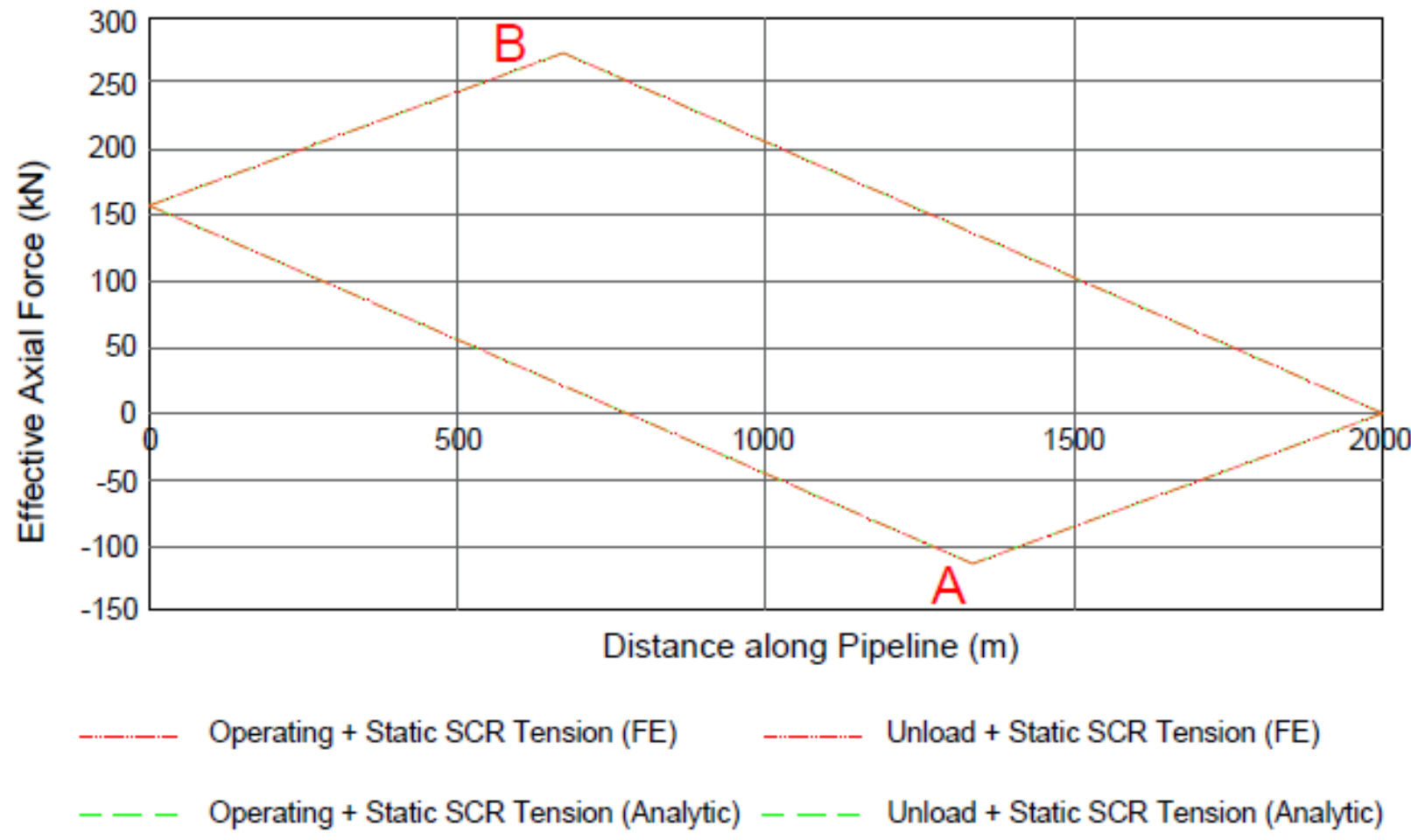

Figure 11: Effective Axial Force Profile-Load/Unload

\section{Pipeline Response - During normal operation and a 1-year storm}

Figure 12 predicts the effective axial force during a 1 year storm in the far field and the near field positions. During the far field position, the SCR bottom tension is resisted by the soil. In this case the anchor point (A) moves to point (F), resulting in a longer segment of the pipeline expanding towards the SCR.

On the other hand, the SCR tension drops under near field storm positions, resulting in a contracting length of the pipeline between KPO and point $(\mathrm{N})$. The contraction causes the soil axial friction to progressively increase with the pipe movement (in the opposition direction of the near offset) until the virtual anchor is reformed. 


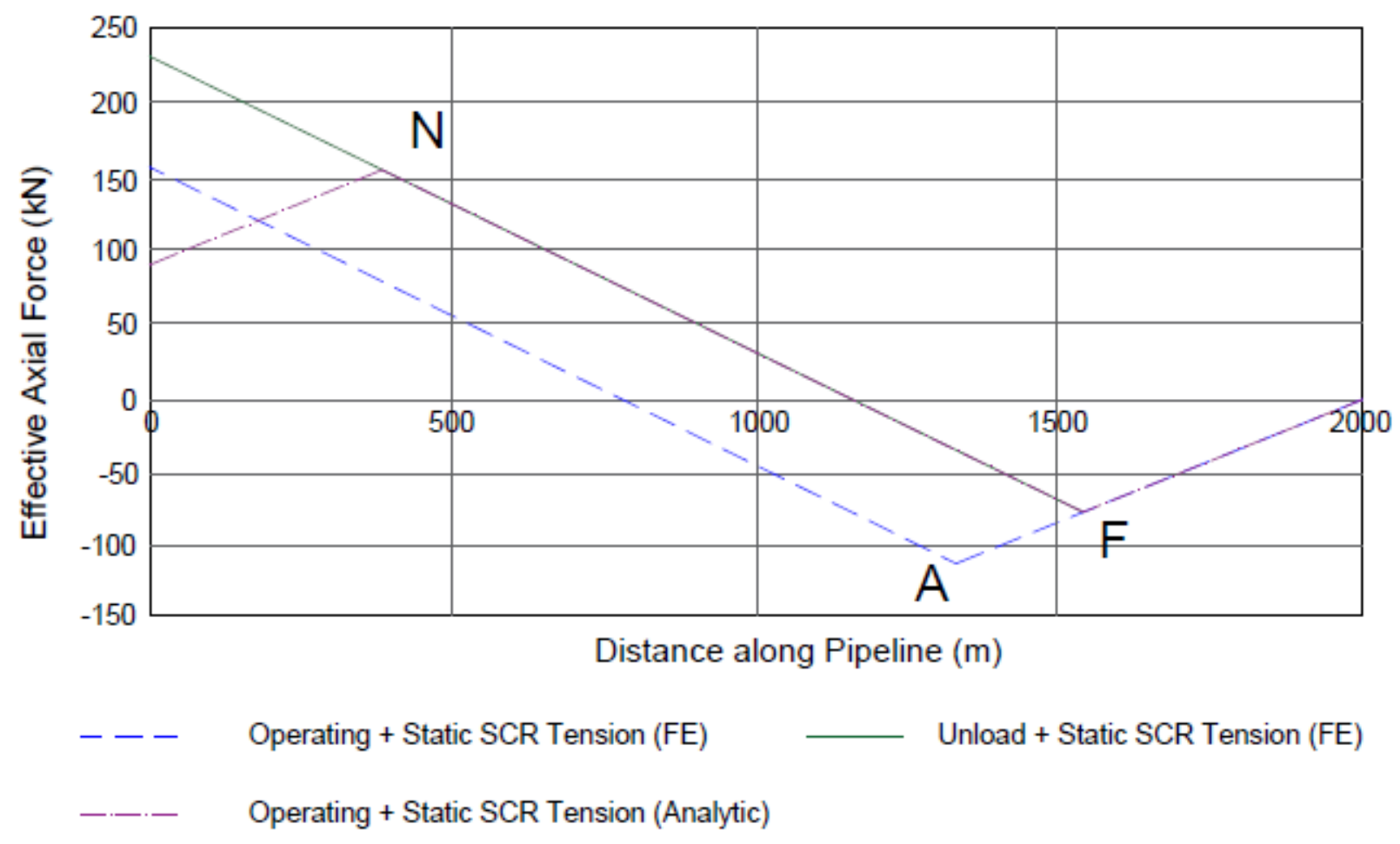

Figure 12: Effective Axial Force Profile-Operation / 1 year storm

\subsection{Parametric Study}

This section provides insights into the driving mechanisms of pipeline design when connecting to the SCR via a sensitivity study on the effect of the SCR tension, the soil friction and friction mobilization distance. In this section the following three walking mechanisms are considered in the finite element simulations, shown in Figure 6, which could result in variations of the mean position of the touchdown point:

- Tension at the pipeline end associated with the SCR;

- Thermal gradients along the pipeline during the repeated start-up and cool-down cycles, and

- Global seabed along the pipeline.

\section{Effect of the SCR Bottom Tension}

The results of this analysis are presented in Figure 13. It can be seen from figure 12 that the direction of the walking induced by the SCR tension force is opposite to the direction induced by both thermal gradients and the seabed slope. Specifically, the pipeline walks towards the SCR as on-bottom SCR tension overcome the thermal transient effects and the seabed slope. 


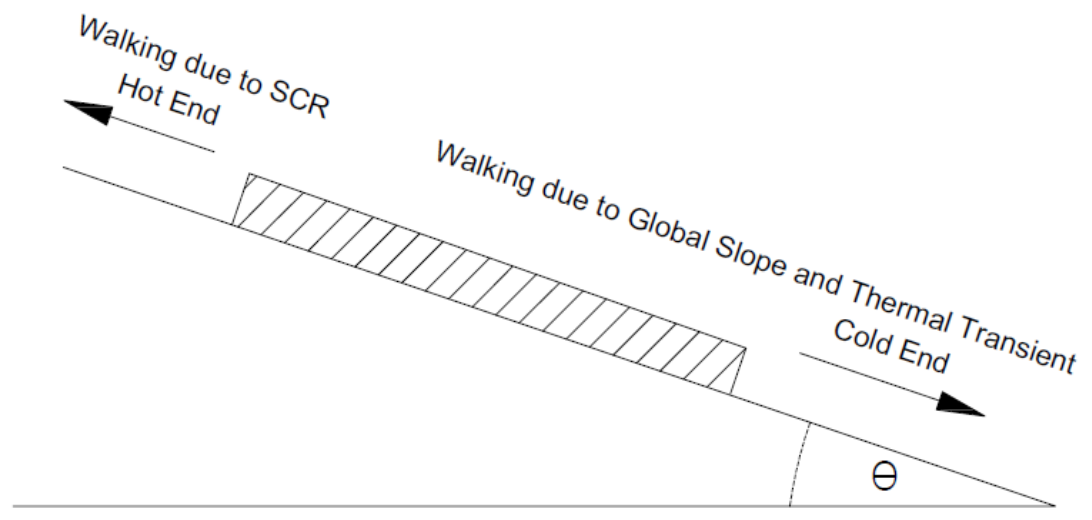

Figure 13: Walking directions

A sensitivity assessment was undertaken to determine the effect of the SCR bottom tension on the rate of walking compared to the effect of thermal transients and seabed slope. A range of SCR bottom tensions were applied as per Table 2. The axial friction coefficient was set to 0.4 with a mobilization distance of $0.00005 \mathrm{~m}$. Refer to Figure 5 for the definition of the mobilization distance.

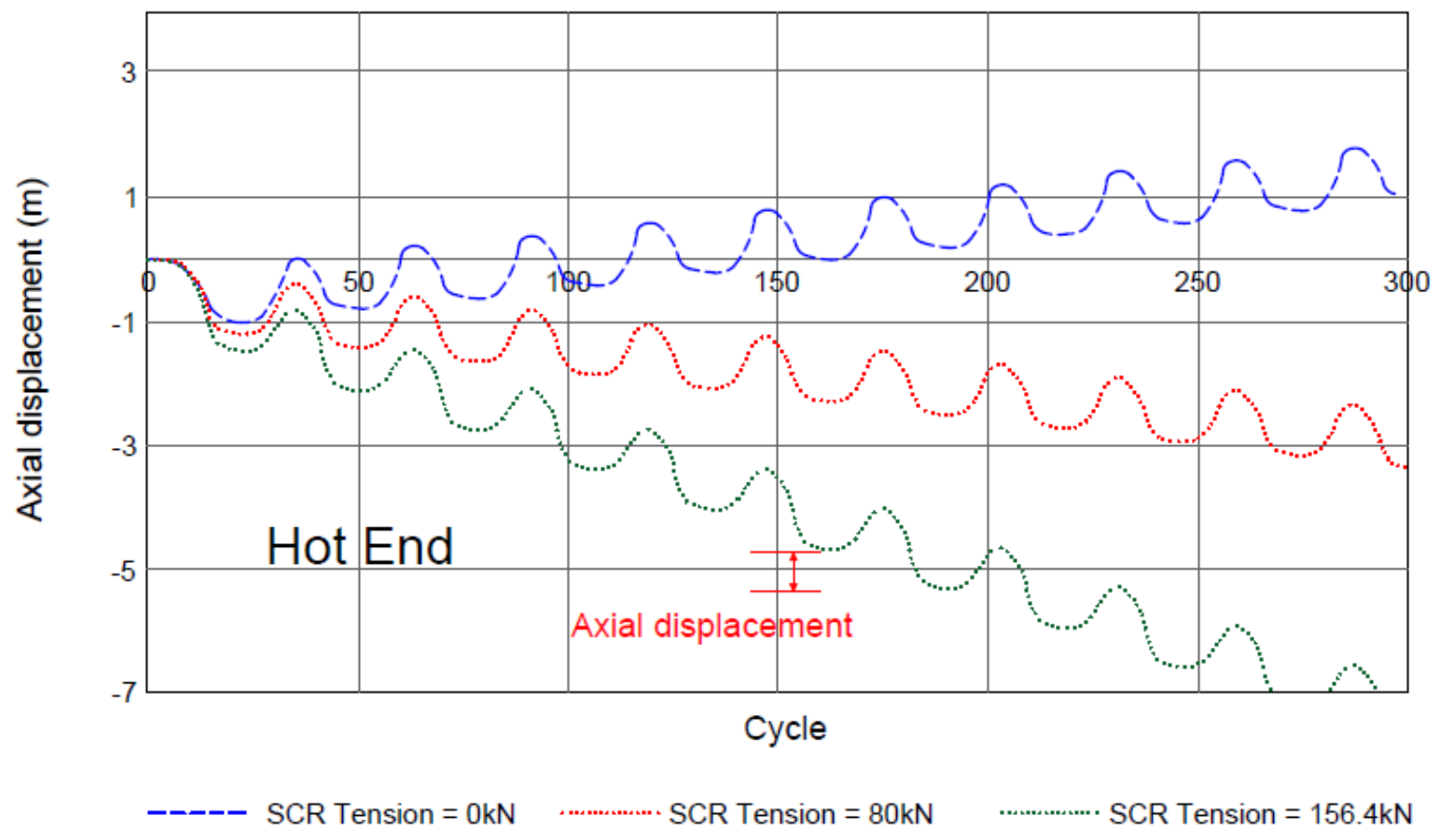

Figure 14: Walking Response - Hot End 
Table 2: Pipeline walking distance for Range of SCR bottom tensions

\begin{tabular}{|c|cc|}
\hline $\begin{array}{c}\text { SCR Bottom Tension } \\
\text { (kN) }\end{array}$ & $\begin{array}{c}\text { Walk Rate per Cycle } \\
\text { (m) }\end{array}$ \\
\hline Zero Tension & +0.23 & (away from SCR) \\
\hline 80 & -0.20 & (towards SCR) \\
\hline 156.4 & -0.63 & (towards SCR) \\
\hline
\end{tabular}

Looking at the results shown in Table 2, Figure 14 and Figure 15, it is obvious that the displacement per cycle for the mean tension value of $156.4 \mathrm{kN}$ is significant and that the total displacement towards the SCR would not be acceptable for a small number of cycles.

As it can be seen from the results shown in Figure 14 and Figure 15 for all cases, the displacement per cycle for the hot end is equal to the displacement per cycle for the cold end. This is another way for validating the finite element model used to establish the results in the paper.

If the maximum allowable axial feed-in towards the SCR is assumed to be $5 \mathrm{~m}$, the results associated with tension of $156.4 \mathrm{kN}$, in Figure 14, show that after a few cycles the displacement towards the SCR would greatly exceed that limit. This deviation would jeopardize the integrity of the SCR if the hold back anchor is not used. The results in green in Figure 15 show that the cold end moves towards the hot end, and this can cause over-stressing of the spool.

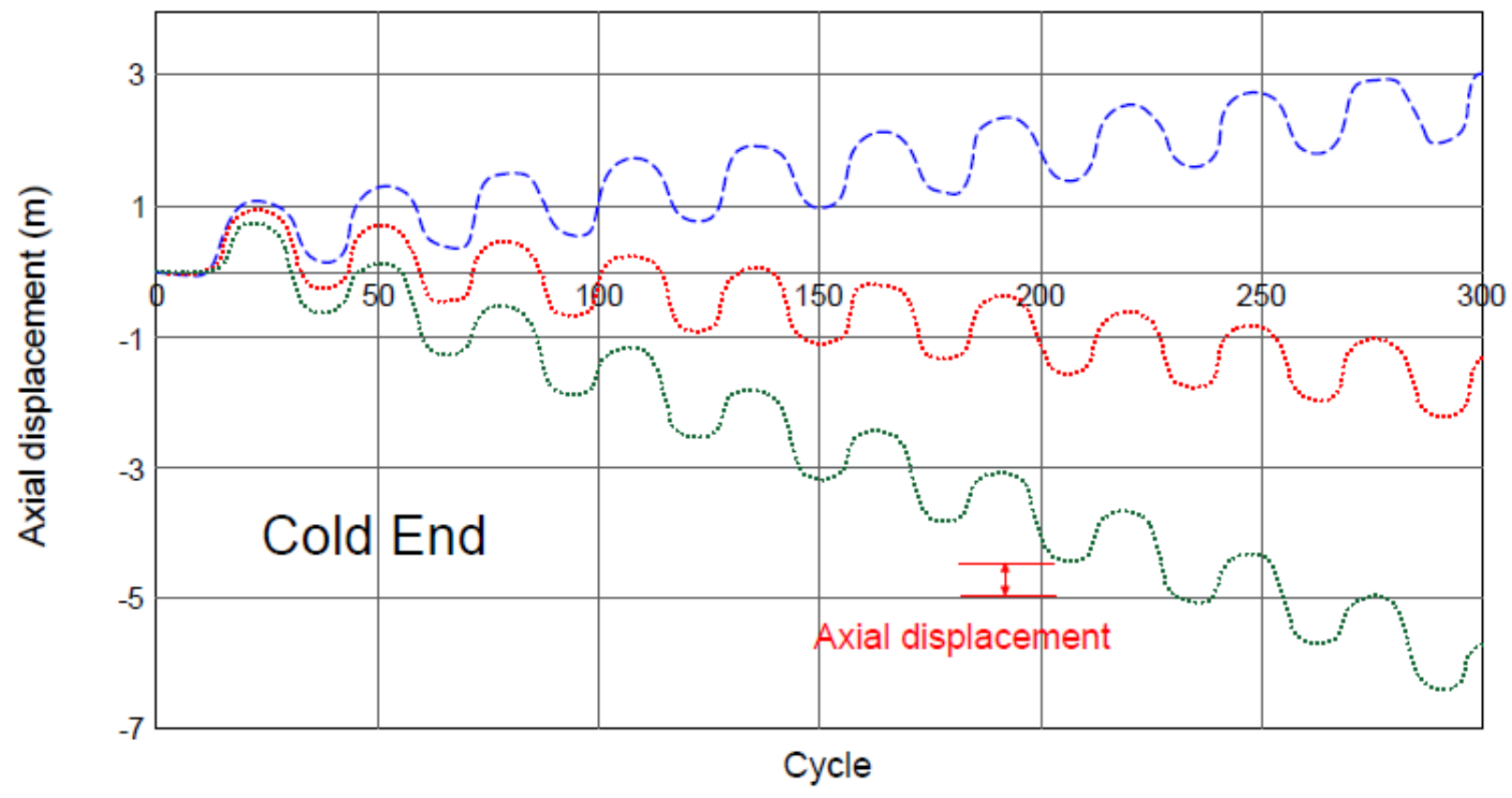


For a tension value of $80 \mathrm{kN}$, the whole pipeline moves towards the SCR, but to a lesser extent than that obtained with the SCR tension of $156.4 \mathrm{kN}$. For the case without SCR tension, the entire pipeline moves towards the cold end as expected. This is due to the combined effect of the thermal transients and the seabed slope. When no SCR tension is used, the walking induced by the transient profile and seabed slope is still present. In this case, the entire pipeline moves towards the cold end (down the slope). The above results also show that an ideal SCR tension could be provided to counteract any mean pipeline walking.

\section{Effect of the Axial Friction}

The model used in this section is presented in Figure 6. A range of axial friction coefficients were applied as per Table 3. The SCR tension was set to $156.4 \mathrm{kN}$ with a mobilization CONSISTENT distance of 0.00005 $\mathrm{m}$. Based on the results presented in Table 3, Figure 16 and Figure 17, it can be concluded that the walking is very sensitive to the axial friction. With the range of possible soil friction coefficient used in the section, the walking behaviour may change substantially as demonstrated in the results.

Table 3: Pipeline walking distance for Range of Frictions

\begin{tabular}{|l|c|}
\hline $\begin{array}{c}\text { Axial Friction } \\
\text { Coefficient }\end{array}$ & $\begin{array}{c}\text { Walk Rate per Cycle } \\
\text { (m) }\end{array}$ \\
\hline 0.4 & -0.63 (towards SCR) \\
\hline 0.8 & -0.21 (towards SCR) \\
\hline 1.2 & -0.05 (towards SCR) \\
\hline
\end{tabular}

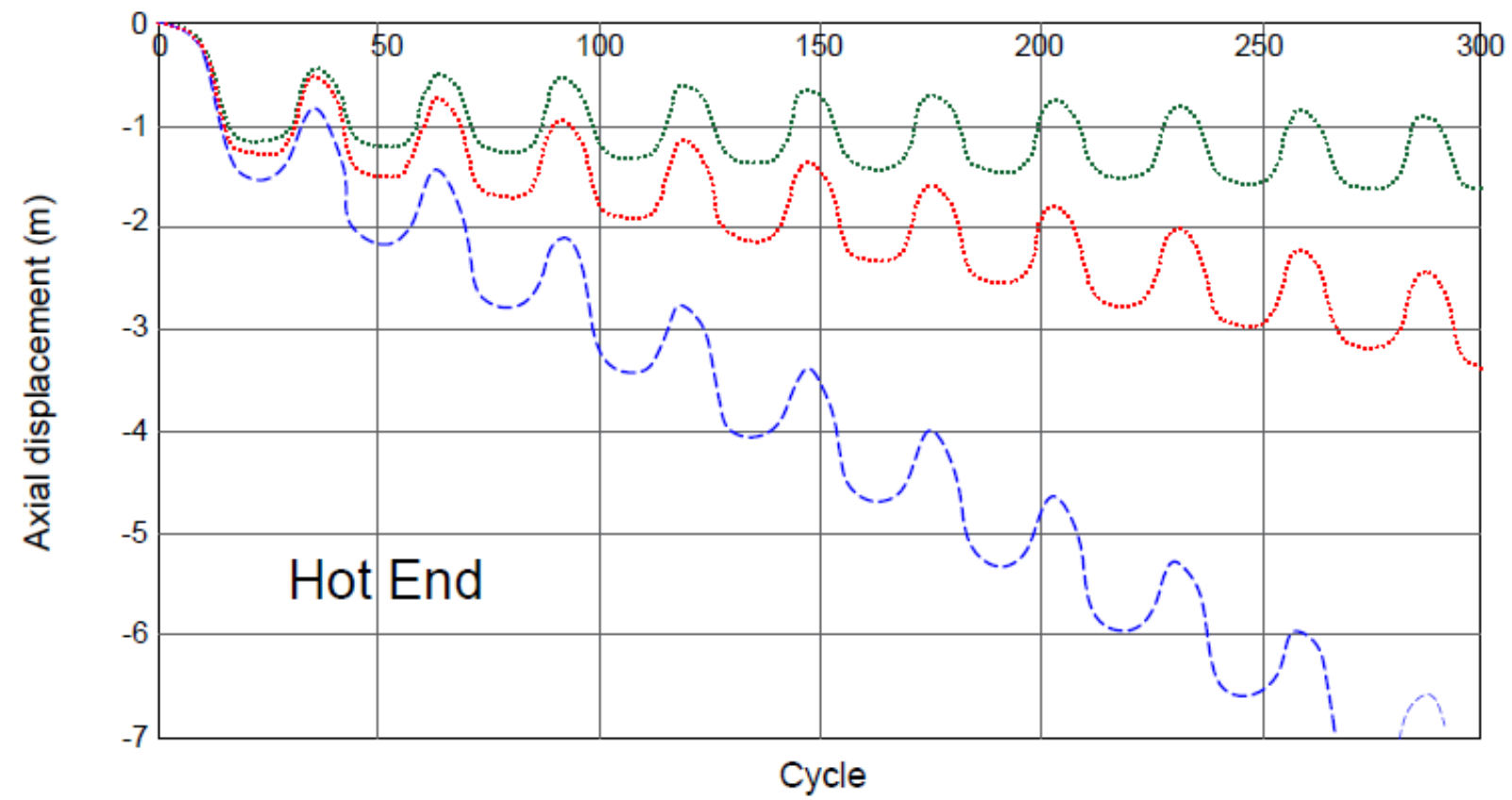

Axial Friction $=0.4$

Axial Friction $=0.8$

Axial Friction $=1.2$

Figure 16: Walking Response - Hot End 


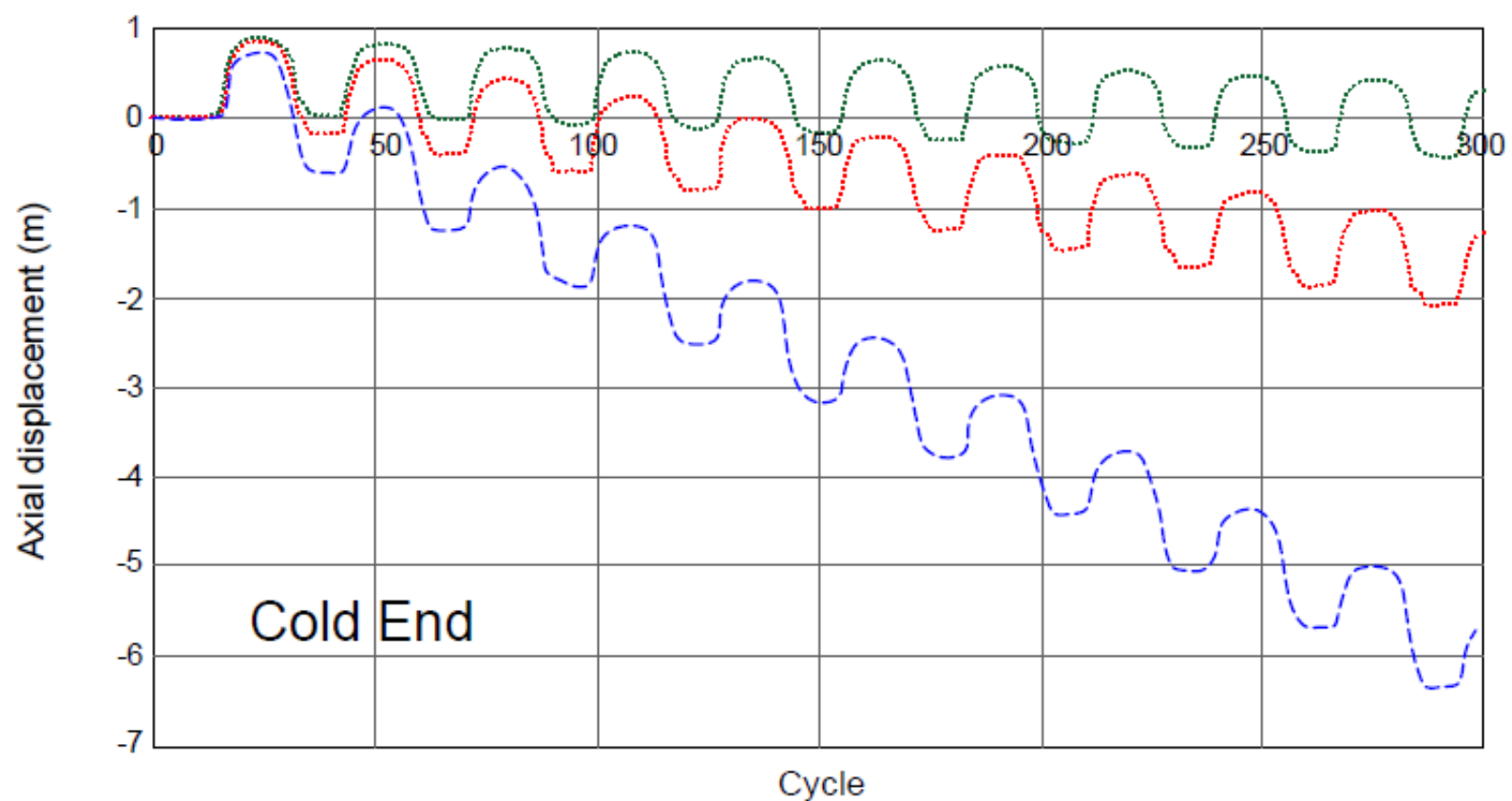

Axial Friction $=0.4$

Axial Friction $=0.8$

Axial Friction $=1.2$

Figure 17: Walking Response -Cold End

\section{Effect of the Axial Mobilization Distance}

The model used in this section is presented in Figure 6. A range of axial friction coefficients were applied as per Table 4. The SCR tension was maintained constant at $156.4 \mathrm{kN}$ with an axial friction coefficient of 0.4 .

Table 4: Pipeline walking distance for Range of Mobilisation Distances

\begin{tabular}{|c|c|}
\hline $\begin{array}{c}\text { Mobilization } \\
\text { Distance }(\mathbf{m m})\end{array}$ & $\begin{array}{c}\text { Walk Rate per Cycle } \\
(\mathbf{m})\end{array}$ \\
\hline 0.05 & -0.613 (towards SCR) \\
\hline 3.36 & -0.610 (towards SCR) \\
\hline 8.4 & -0.600 (towards SCR) \\
\hline 90 & -0.49 (towards SCR) \\
\hline
\end{tabular}

The results in Table 4, Figure 18 and Figure 19 show that the rate of axial walking reduces with the increasing the mobilization distance. Furthermore, it is evident from Table 4 that the mobilization distance could have substantial impact on shorter pipelines. 


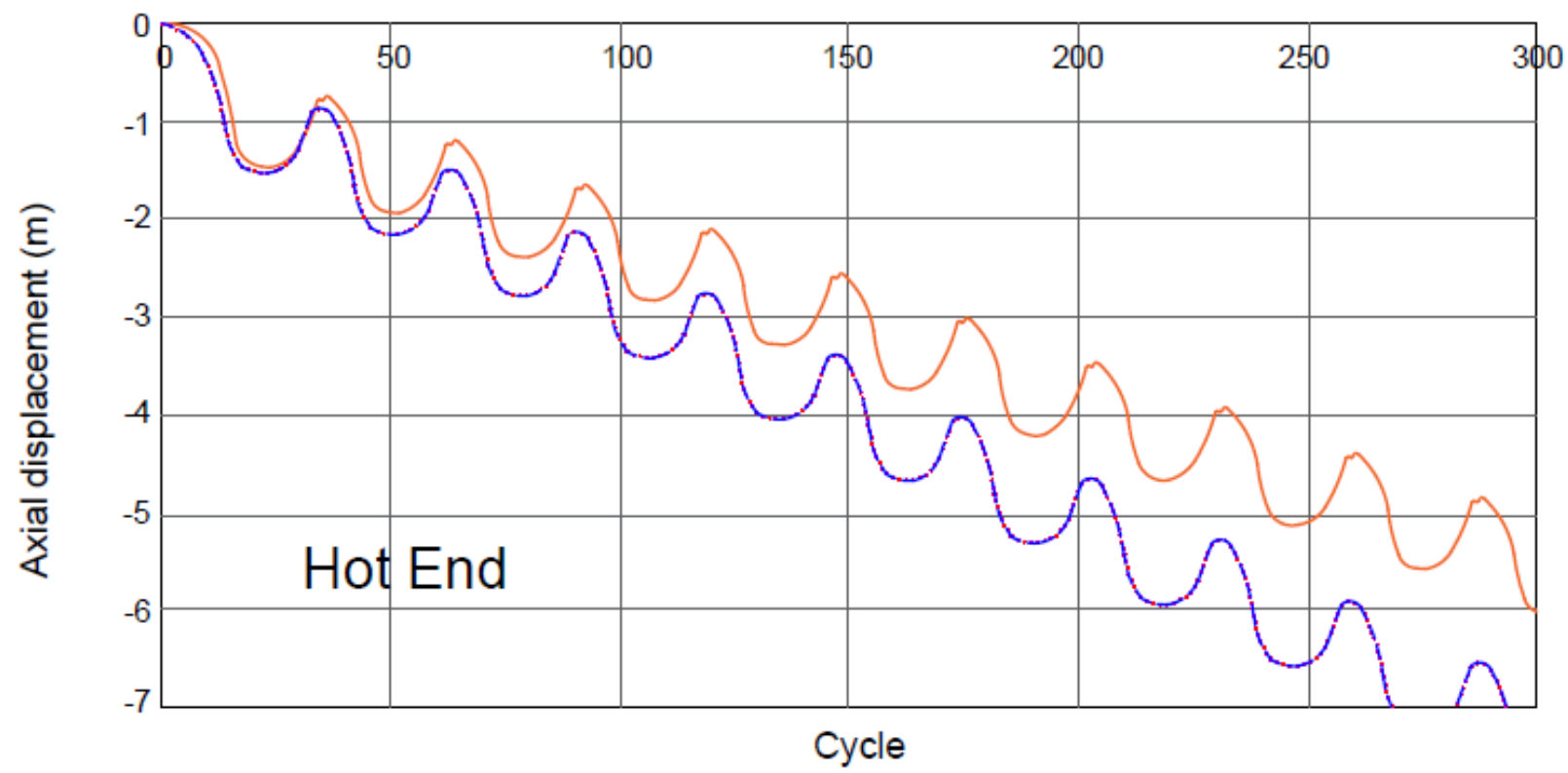

Mobilisation Distance $=0.05 \mathrm{~mm}$

Mobilisation Distance $=3.36 \mathrm{~mm}$

Mobilisation Distance $=8.4 \mathrm{~mm}$

Mobilisation Distance $=90 \mathrm{~mm}$

Figure 18: Walking Response - Hot End

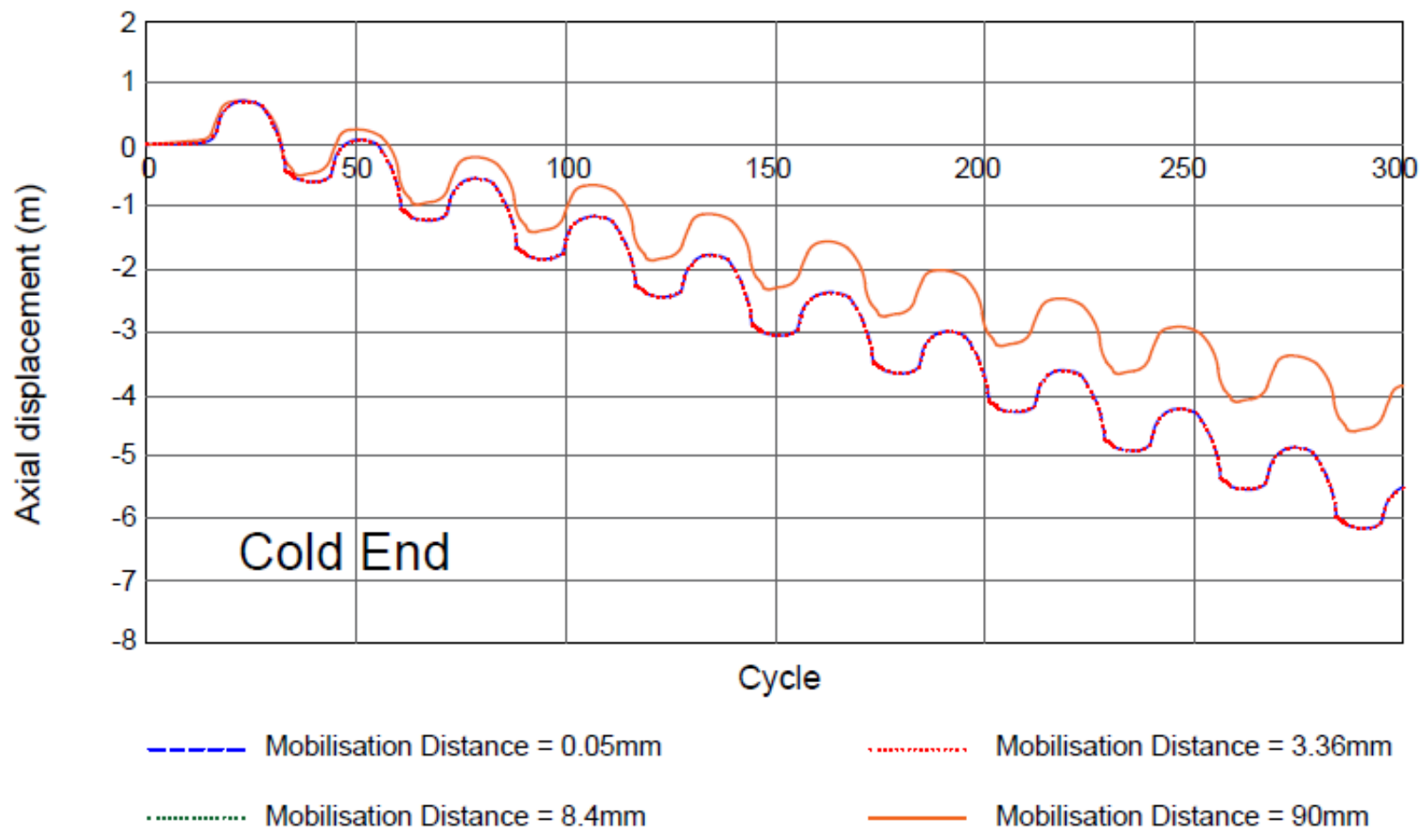

Figure 19: Walking Response - Cold End 


\subsection{Requirements for Anchorage}

This section presents the criteria that must be satisfied during the design of the pipeline/SCR system to use hold-back anchors along the pipeline.

\subsection{Pipeline Slippage}

Is a pipeline connected to an SCR susceptible to slippage due to SCR tension?

A short pipeline connected to a SCR is prone to slippage by the SCR during the storm conditions (i.e. extreme and survival design load cases).

The pipeline length, the axial friction coefficient as well as the SCR bottom tension in the far field position govern Pipeline slippage. Pipeline slippage causes the pipeline to move axially towards the SCR, therefore, compromising the integrity of the SCR and the expansion spool installed at the PLET.

\section{Illustrative Example}

This example illustrates the phenomenon of pipeline slippage due to SCR tension. In this example, a short pipeline is connected to a SCR as shown in Figure 20. The pipeline is straight without any route curve. The SCR is subjected to the vessel offset in the far field position.

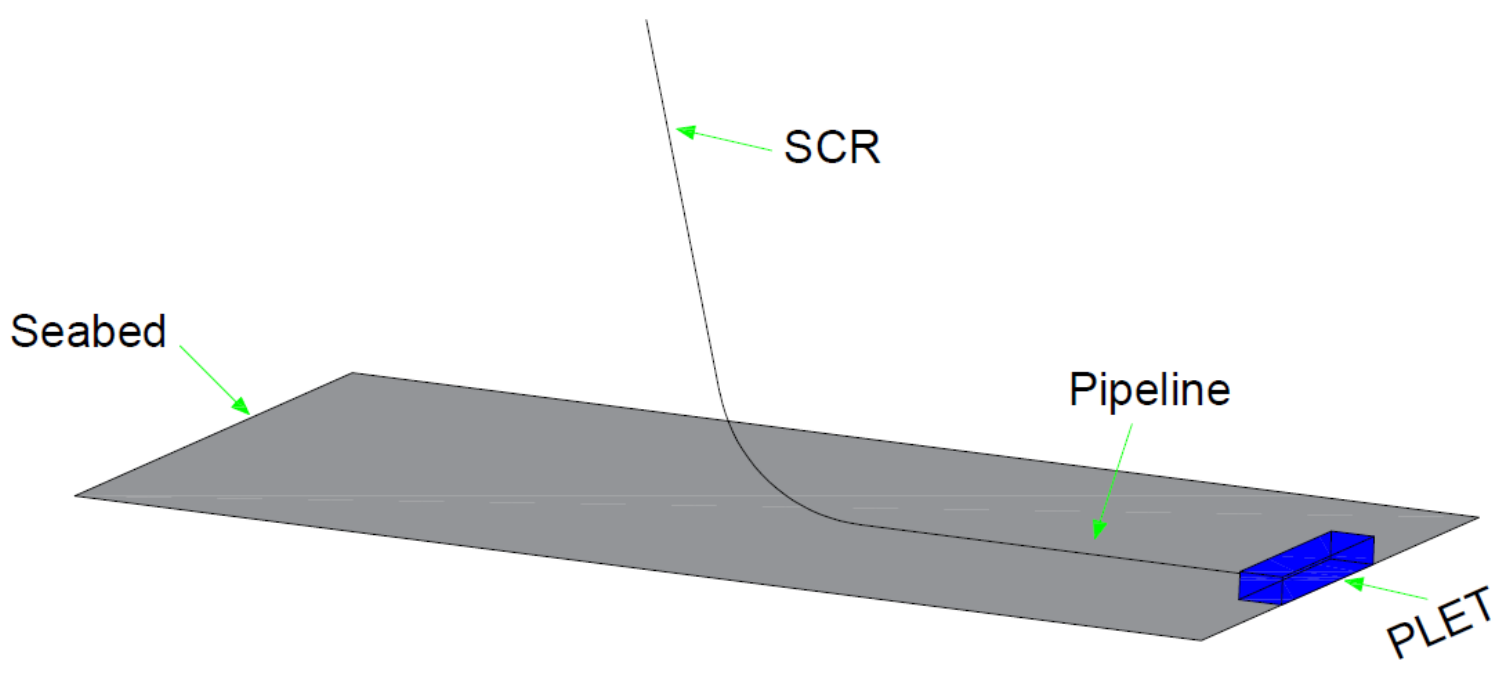

Figure 20: slippage - demonstration example

Error! Reference source not found. shows the effective axial force obtained from finite element modelling using ABAQUS [9] for different axial friction coefficients. The effective axial force profile is dependent on the combined effect of the axial friction coefficient and the value of the SCR tension. The coordinate values 0 and 2000 on the $x$-axis refer to the transition point and the free end, respectively.

It can be seen from Error! Reference source not found. and Figure 22 that the pipeline is prone to slippage only for the lower bound value of the axial friction coefficient. In this case, the whole pipeline moves axially towards the SCR. Figure 5 showed previously that pipeline expands approximately $-1.5 \mathrm{~m}$ and +0.8 $\mathrm{m}$ towards the SCR and free end respectively when the upper bound axial friction coefficient was sued. 
For the best estimate value of the axial friction coefficient, the end expansions are $-1.9 \mathrm{~m}$ and $+0.5 \mathrm{~m}$ towards the SCR and the free end, respectively. The positive and negative signs indicate that the pipeline expands towards the free end and towards the SCR, respectively. Figure 23 shows that the entire pipeline displaces towards the SCR with a value of $29.8 \mathrm{~m}$ YOU HAVE ALREADY GIVEN THE DIRECTION.

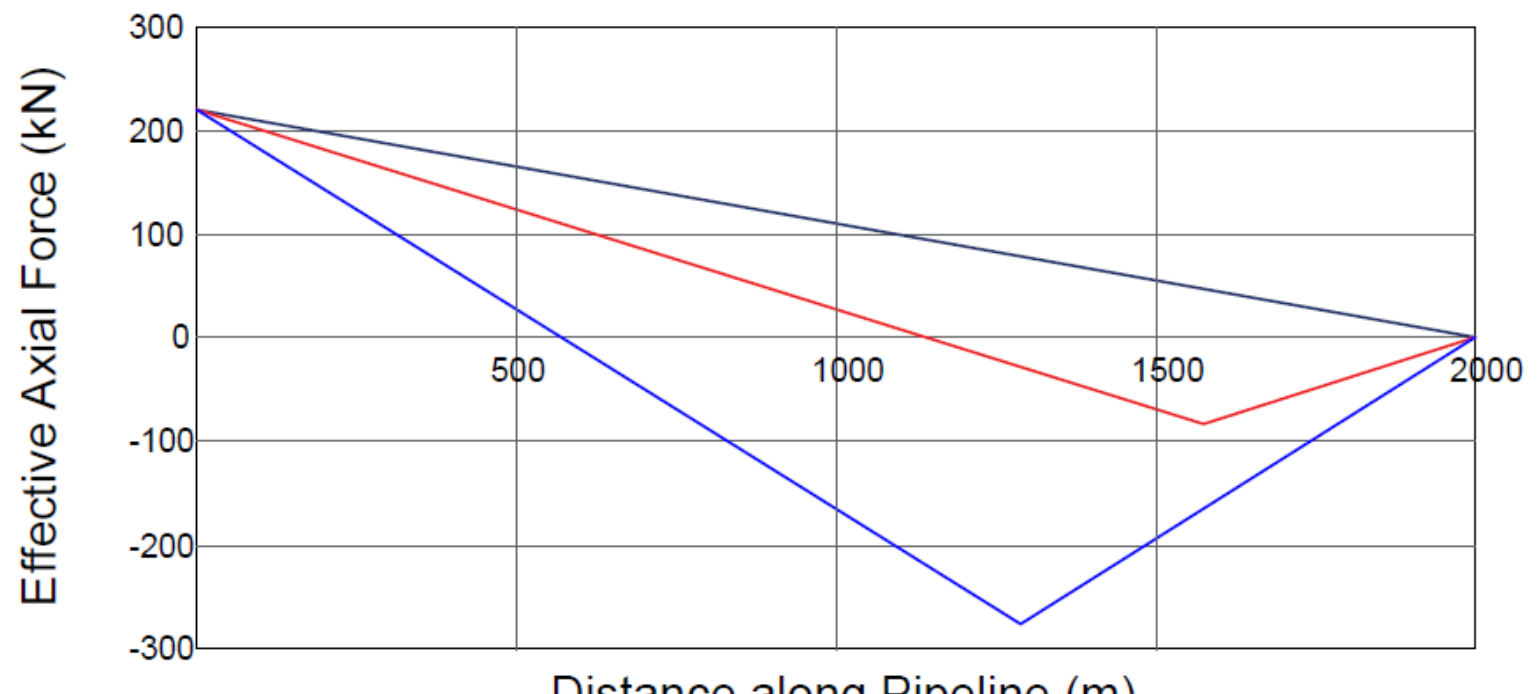

Distance along Pipeline $(\mathrm{m})$

Upper bound axial friction

Best estimate axial friction

Lower bound axial friction

Figure 21: Effective axial force vs. distance at different axial friction coefficient

In order to prevent the pipeline slippage towards the SCR, it is recommended to install a hold-back anchor either at the PLET side away from the SCR transition point or at the SCR transition point. This can be decided based on the SCR axial feed-in limit. If the pipeline expansion associated with the pressure and temperature changes in the direction of the SCR is less than the SCR axial feed-in limit, then the recommended anchor location will be at the PLET as per [1]. If the pipeline expansion towards the SCR is greater than the SCR axial feed-in limit, then the hold-back anchor should be installed at the SCR transition point. The transition is the point where there is no lateral or vertical movement due to the dynamics of the SCR [1]. 


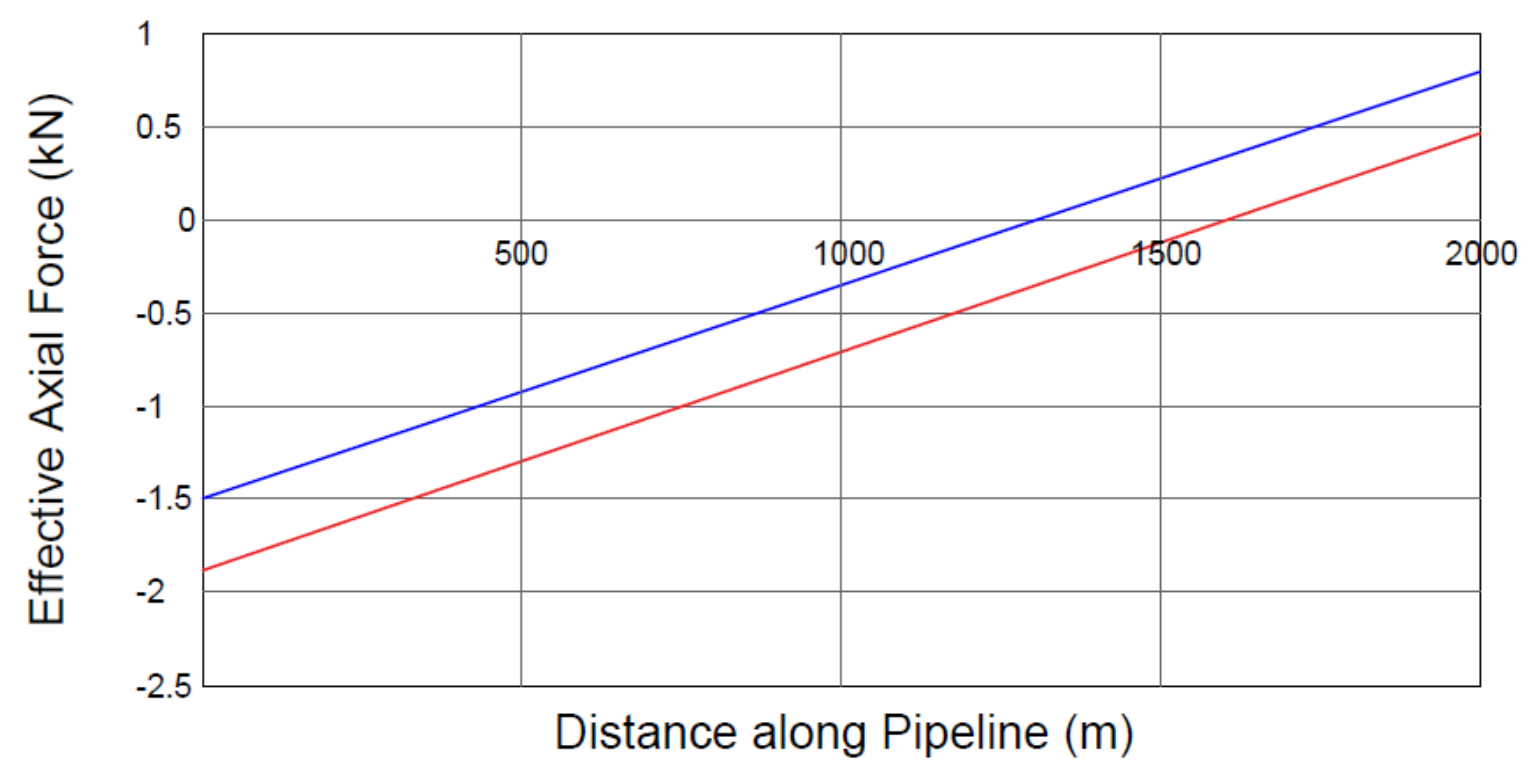

Upper bound axial friction

Best estimate axial friction

Figure 22: Axial displacement vs. distance for upper bound and best estimate axial friction coefficients

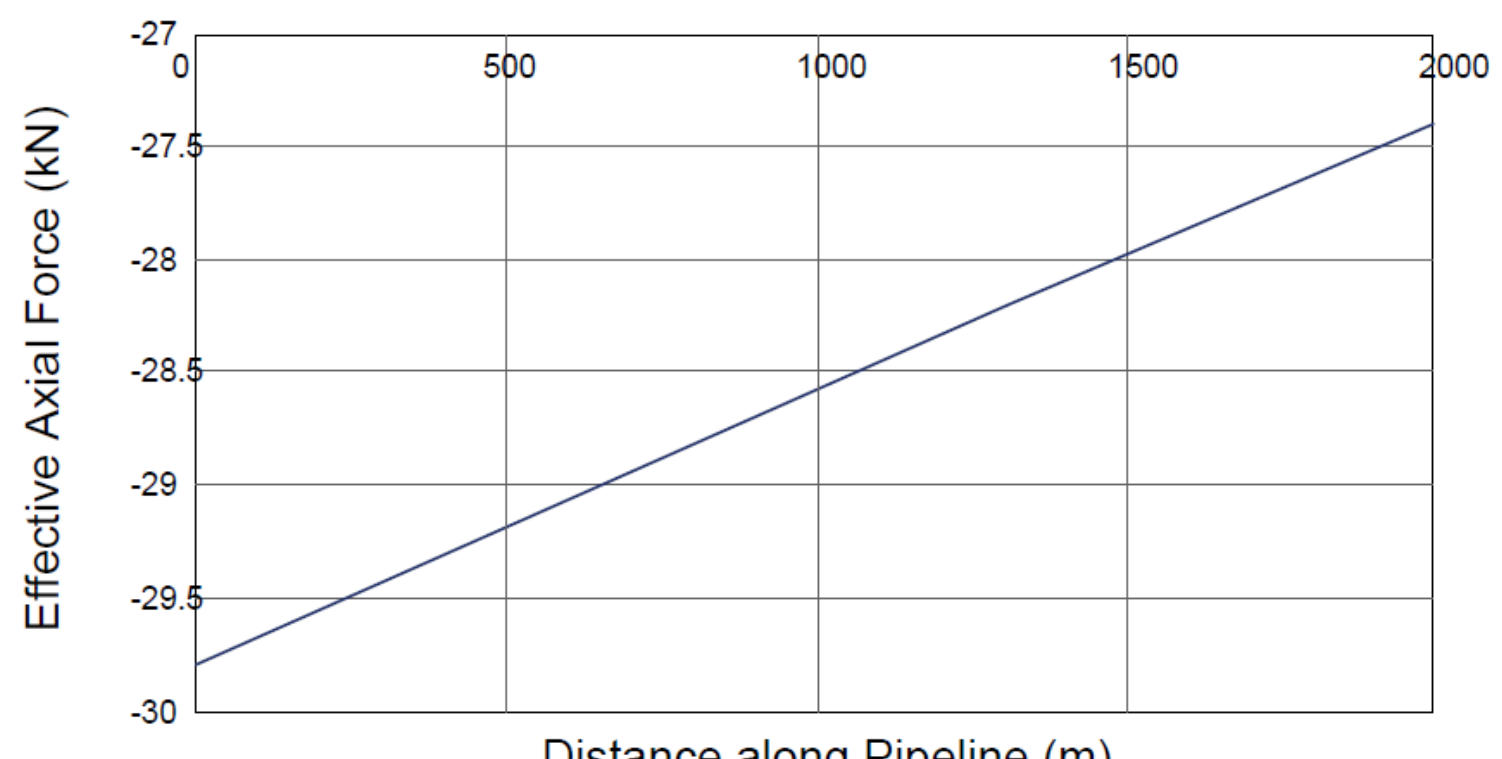

Distance along Pipeline $(\mathrm{m})$

Lower bound axial friction

Figure 23: Axial displacement vs. distance for t lower bound axial friction coefficient

The following equation can be used to determine whether a short pipeline that is connected to a SCR is susceptible to pull-out/slippage: 
Where:

$R_{a}=L \times W_{s} \times \mu_{a}$

L: Straight pipeline length.

$\mu_{a}$ : Axial friction coefficient.

$W_{s}$ : Pipe submerged weight.

Hence, the pipeline length required to prevent the pull-out can be calculated as follows:

$L=\frac{T}{W_{s} * \mu_{a}}$

It can be seen from equation (13) that a high axial resistance and a high pipe submerged weight are generally beneficial in suppressing the pipeline slippage and dropping the need for the anchoring system. The axial resistance can be increased with the increase in the surface roughness of the pipeline coating.

\subsection{Route Bend Pull-out due to SCR tension associated with storm condition}

A significant design issue is whether the route bend is susceptible to pull-out in association with the SCR tension.

Route curves are generally used to align the approach angles of the field to the floating host facility riser hang-off.

Route bend pull-out can occur as a result of excessive tension transmitted from the SCR to the route bend during storm conditions. Route bend pull-out should be obviated for the following reasons:

1. Straightening the route bends will result in the development of non-recoverable end expansion to the SCR. Hence, slippage/pull-out of the mean position of the SCR touchdown point will occur towards the floating production vessel. Otherwise, straightening the route bends could increase the end expansion towards the spool installed at the other end (i.e. compromising the integrity of the spool)

2. Straightening the route bend could lead to significant implications on the field architecture.

\section{Illustrative Example}

In the example shown Figure 24, a SCR is connected to the pipeline with a route curve. In the finite element analysis, the SCR is subjected to the vessel offset in the far field position. It is assumed that the pipeline will remain in operation under the storm conditions. The objective of this example is to show whether the curve/bend could be prone to pull-out under the influence of excessive transmitted tension associated 
with the storm condition. In this example, coordinate values 0 and 3500 on the $x$-axis refer to the transition point and the free end, respectively.

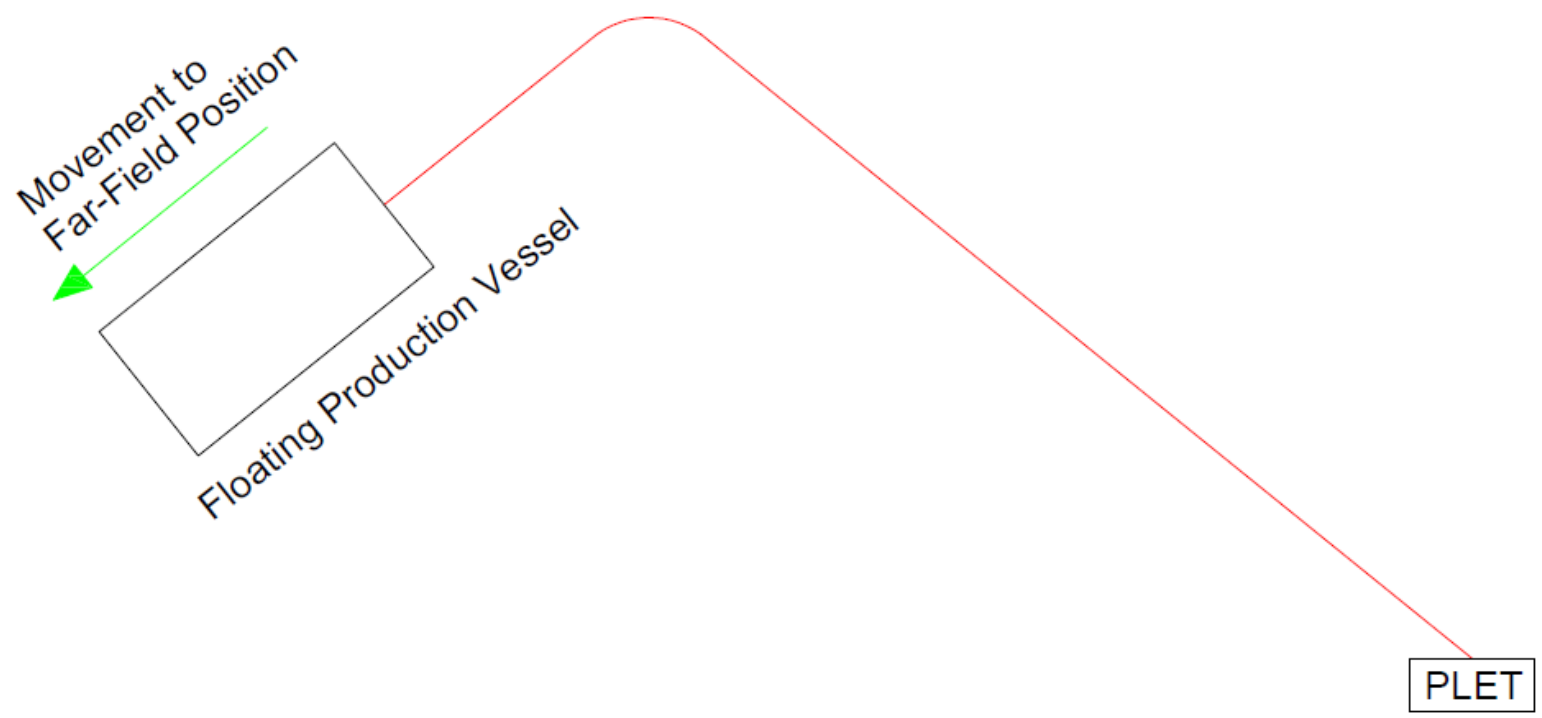

Figure 24: Curved pipeline connected to floating production vessel via SCR

The results presented in Figure 25 and Figure 26 show that excessive SCR tension associated with the storm condition could result in route bend pull-out.

In case the pipeline is found to be prone to route bend pull-out however, the following solutions should be considered first, before adopting the holding back anchor solution:

- Relocate the route bend,

- Introduce a straight pipeline section prior to the route bend, or

- Increase the bend radius of the route bend.

If the above solutions are not successful in preventing the ben pull-out, a hold-back anchor should be employed. The anchor can be installed at the transition point of the SCR. 


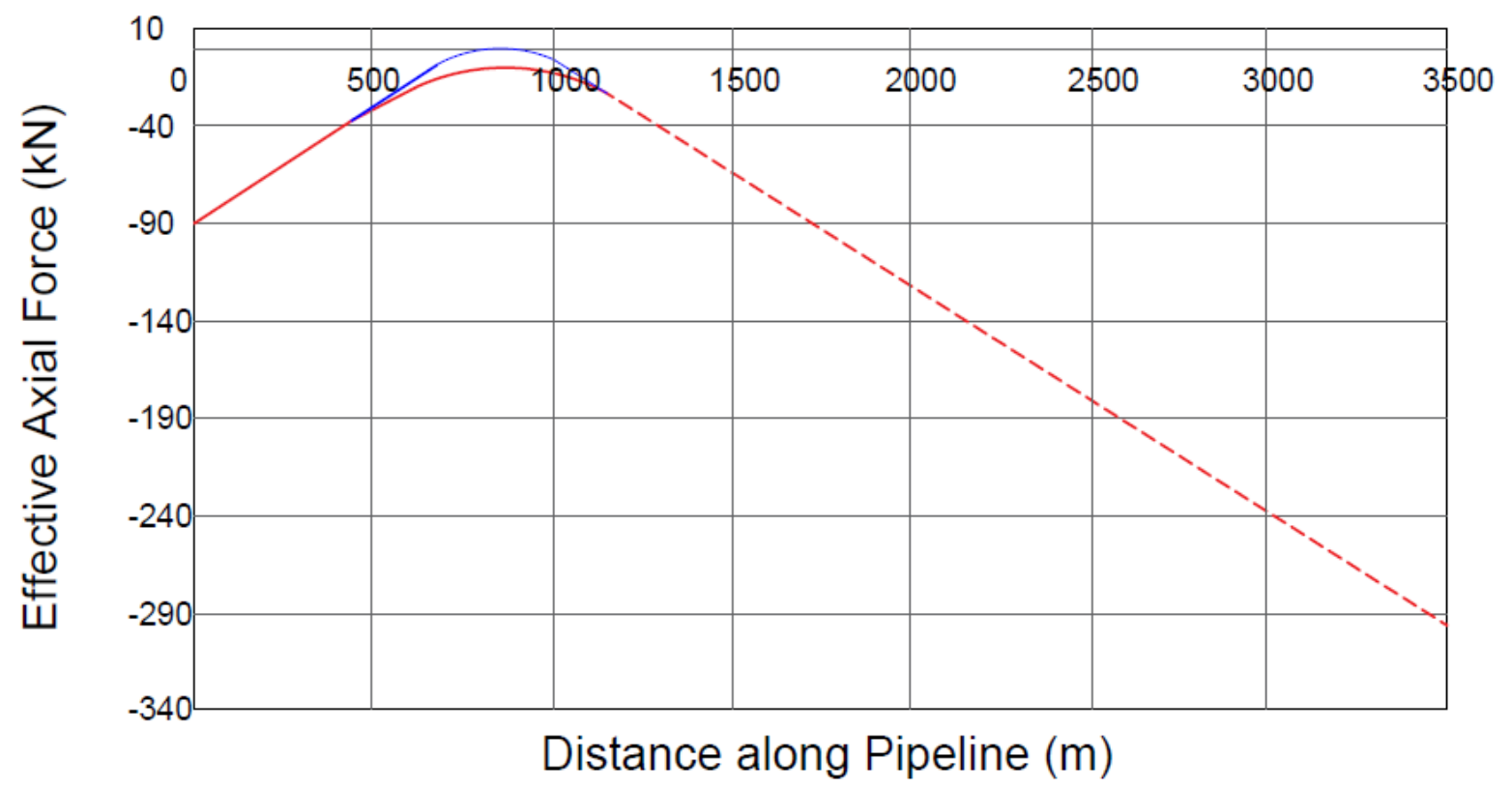

As-laid

Post-storm

Figure 25: Pipeline route after the application of SCR far tension

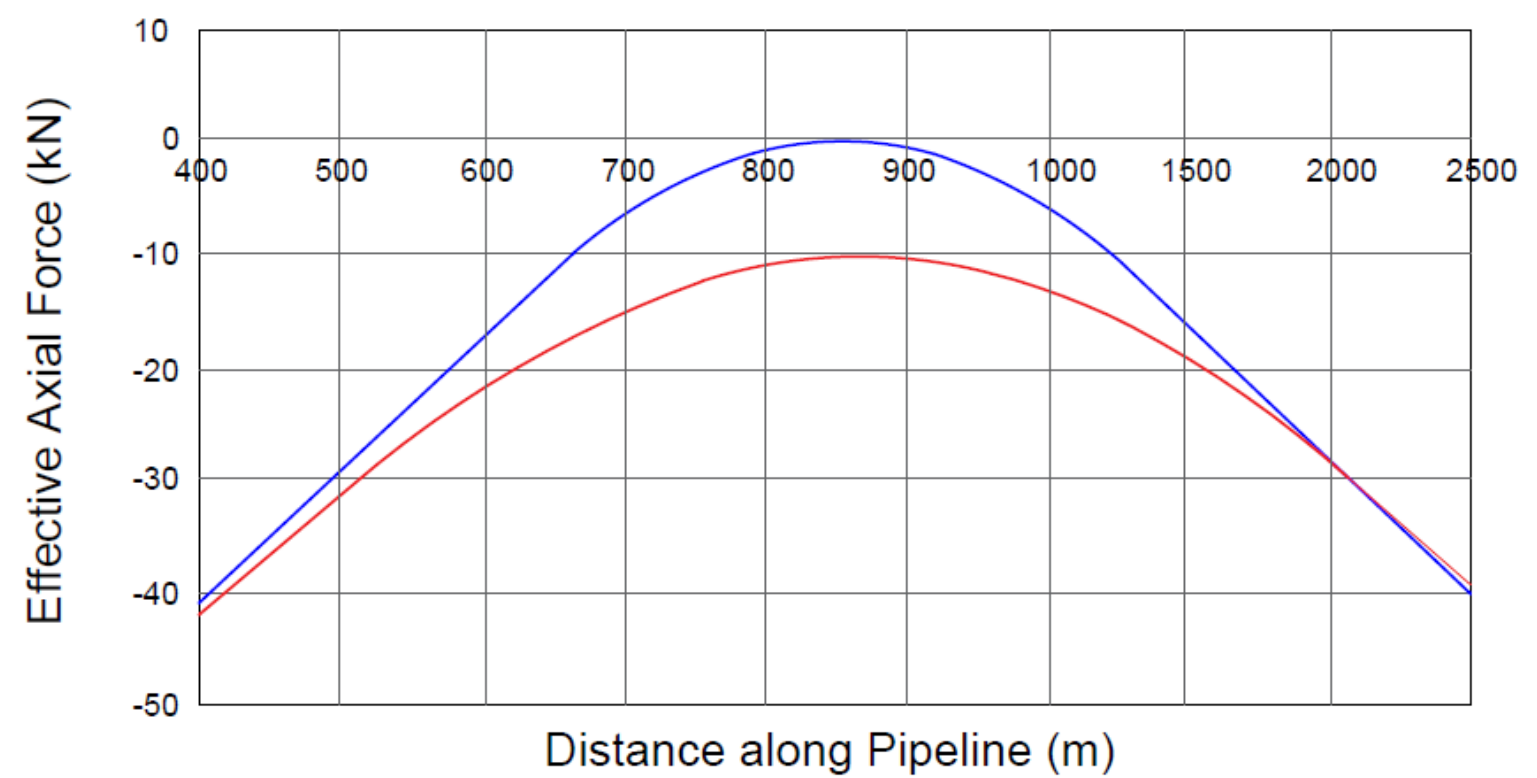

As-laid

Post-storm

Figure 26: Snapshot on route bend 
As per Equation (10), the maximum tension $(T)$ that can be resisted by the route bend is calculated as:

$T=\frac{R \times \mu_{L} \times W_{S}}{S F}$

where:

R: Route bend radius.

$\mu_{L}$ : Lateral friction coefficient (it is recommended to use lower bound).

$W_{s}$ : Pipe submerged weight.

SF: Factor of safety.

\subsection{Is the route bend susceptible to pull-out associated with tension build-up during the repeated operational start-ups and shut- downs?}

Route bend stability under the continuous shut-down is an important requirement during the design of "short" or "ultra-short" high temperature pipelines in deep water. The tension that can result along the length of the pipeline from shut-down conditions can be significantly greater than that resulting during pipe lay. This increase in the pipeline tension can force the route bend to straighten, if the radius is not large enough to provide the required amount of resistance. This problem is further exacerbated with the presence of riser bottom tension in the pipeline.

\section{Illustrative Example}

The example shown in Figure 27 is designed to assess the susceptibility of the route curve to pull-out associated with tension build-up during repeated shut-down cycles. The SCR tension applied in this model is the static SCR tension. The pipeline is subject to eight cases of repeated start-ups and shut-downs. Figure 28 illustrates the effective axial force induced during the loading and unloading conditions for the pipeline system. The red and black dotted lines refer to the centre of the route bend and tensile force at which the route bend becomes unstable. 


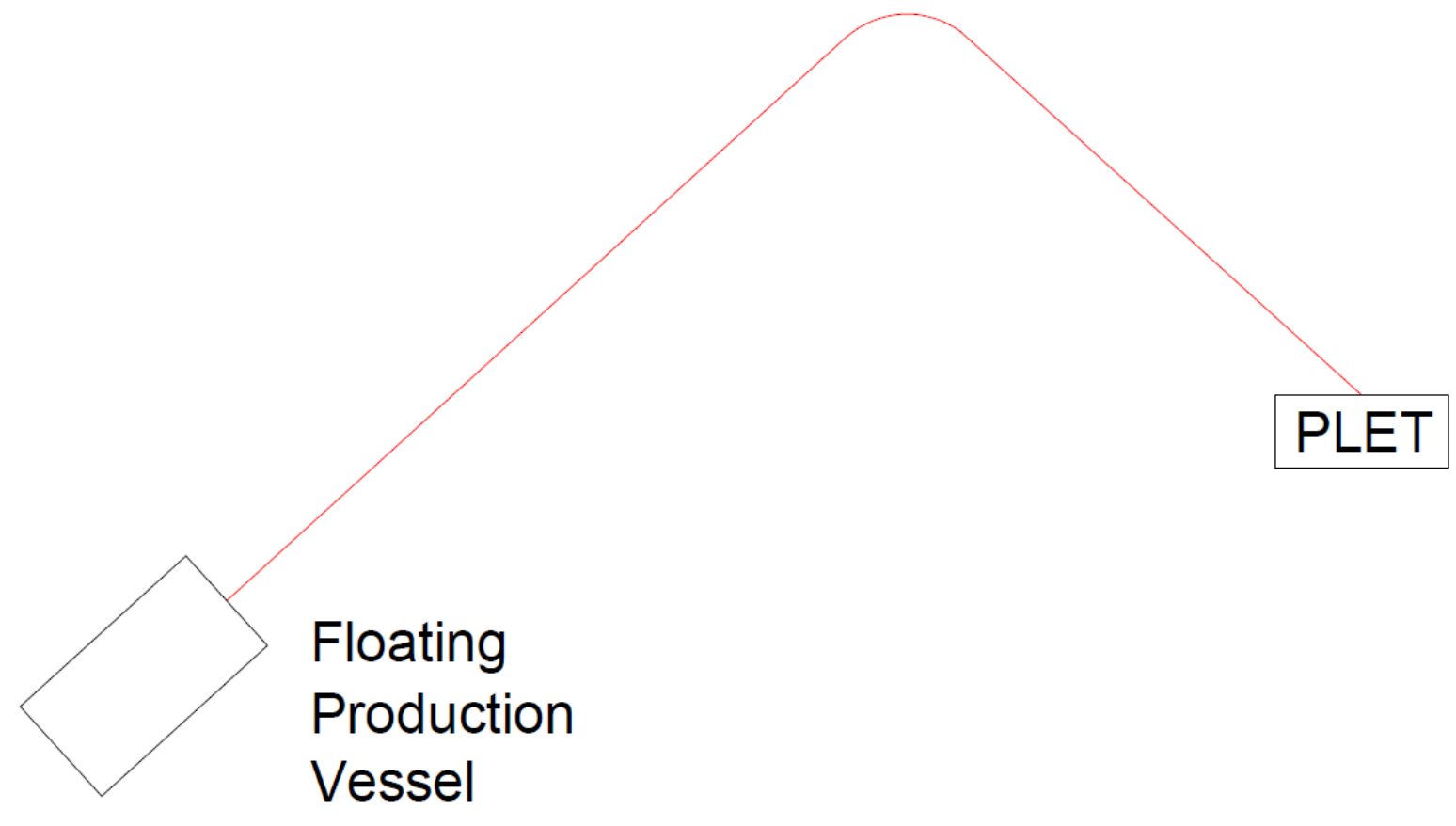

Figure 27: Curved pipeline connected to floating production vessel via SCR

In this example, the destabilising force ( $\left.N_{\text {unstable }}\right)$ is equal to $110 \mathrm{kN}$, calculated using Equation (10).

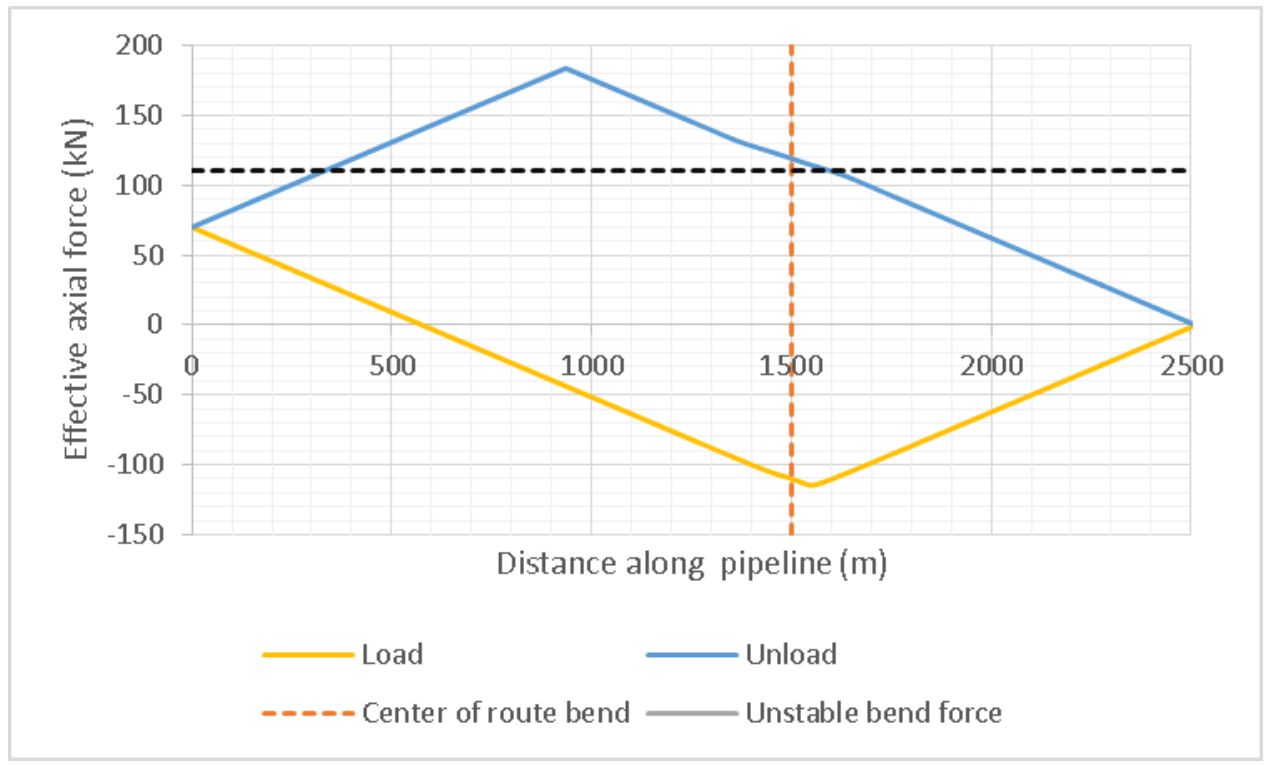

Figure 28: effective axial force during loading and unloading conditions

Figure 28 shows that the effective axial tension at the centre of the bend during the unloading condition is $120 \mathrm{kN}$, which is greater than the destabilising force $\left(\boldsymbol{N}_{\text {unstable }}\right)$. Hence, the route bend will become unstable. This can be explained further by looking at Figure 29, which demonstrates that the route bend 
is unstable under the repeated loading and unloading (start-ups and shut-downs) conditions in the presence of the static SCR tension.

Figure 30 shows the distribution of the axial displacement along the pipeline; it can be seen that the end expansion towards the free end increases with the progress of the route bend pull-out. This proves that the imposed tension would pull-out the route bend, allowing further pipe to feed-in towards the spool or the SCR and hence compromising the integrity of the spool and the SCR if not dully controlled.

In the event that the pipeline proves to favour a route bend pull-out event, the pipeline/SCR should be reconsidered to investigate the possibility of increasing the bend radius. Alternatively, the consequences of the route bend pull-out should be investigated. The consequences of a route bend pull-out event are:

1- Significant implications on the field layout architecture.

2- Increasing the axial feed-in towards the SCR beyond the allowable limit and hence, compromising the integrity of the SCR.

3- Requiring more pipe segments to feed-in towards the spool, hence overstressing the spool.

If the route cannot be adjusted and the consequences are unacceptable, then a hold-back anchor is mandatory.

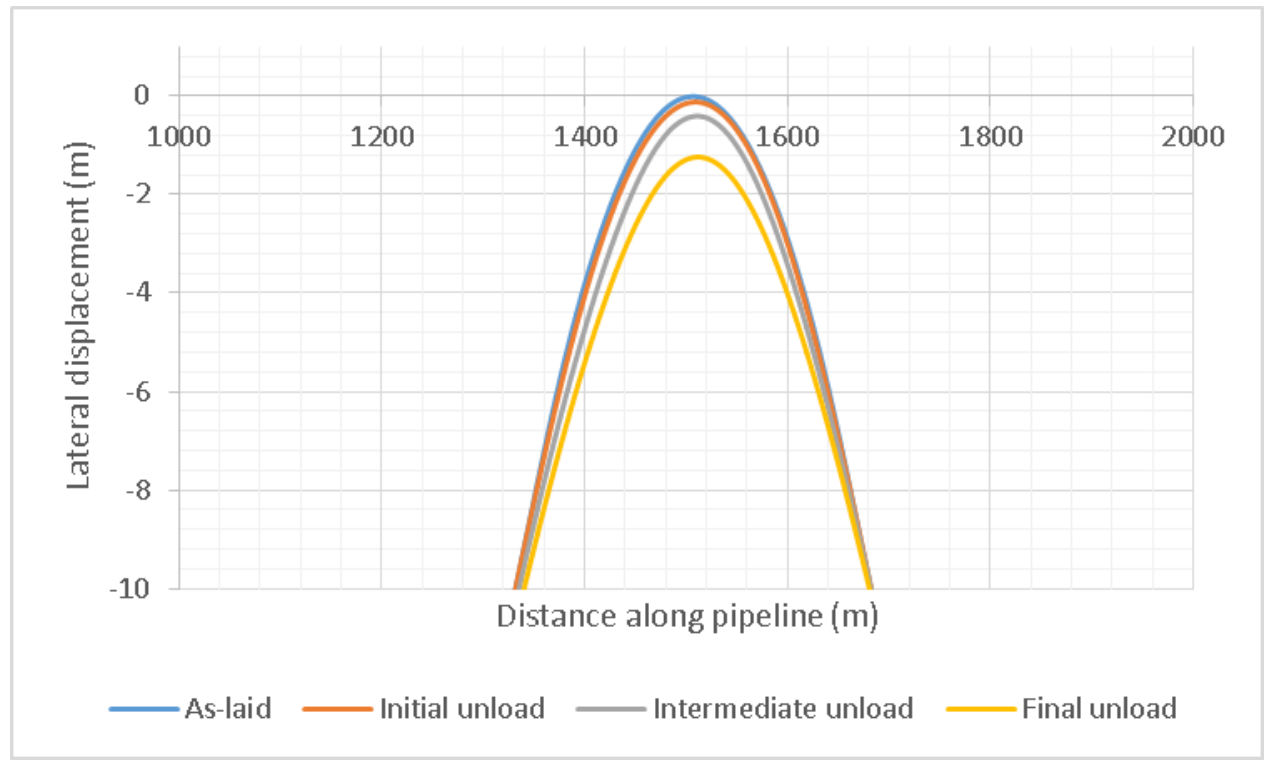

Figure 29: Route bend pull-out 


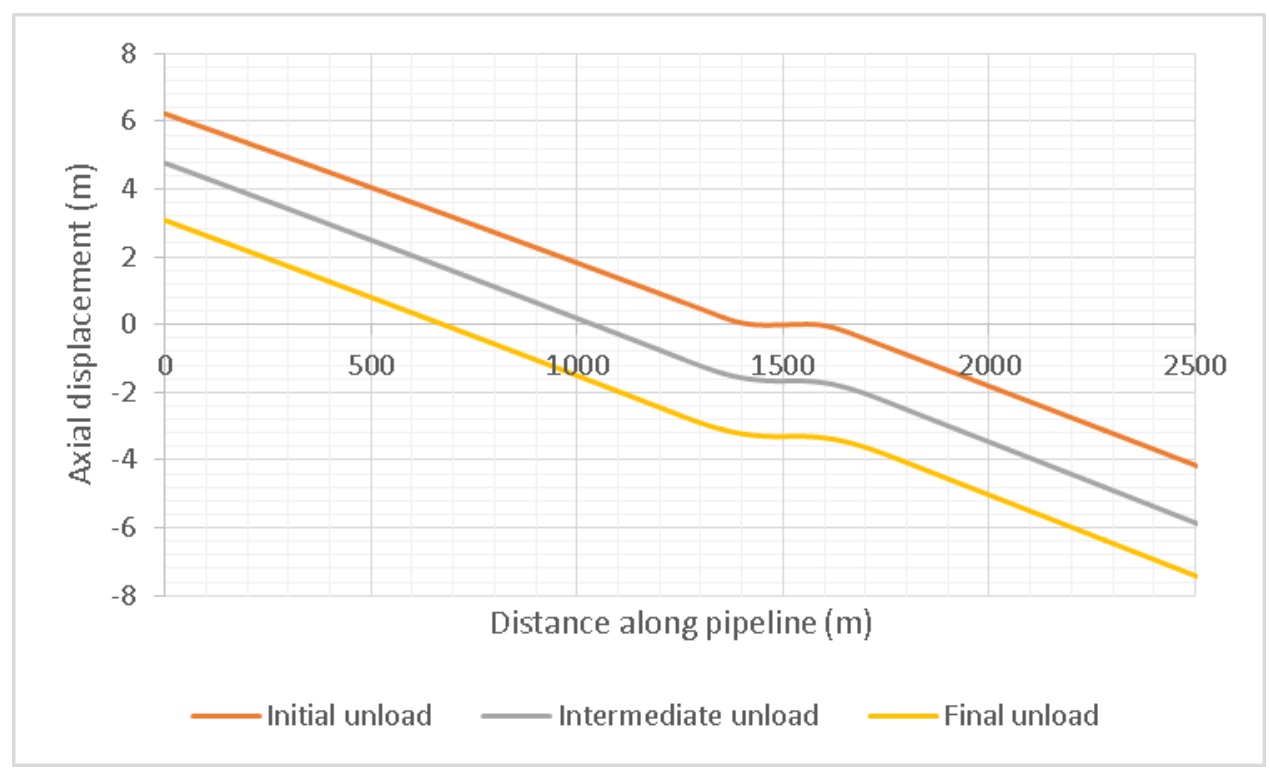

Figure 30: Axial displacement along the pipeline

It should be noted that lateral friction coefficients considered in sections 4.2 and 4.3 are residual/breakout lateral friction coefficients.

In real conditions, as the route bend moves laterally, the influence of SCR tension as well as cyclic start-up/shutdown decreases. With each cyclic sweep, the route bend tends to sweep the surface soil ahead of it to build up into berms at the extremes of the pipeline displacement. These soil berms could offer a significant lateral resistance to route bend lateral movement. The subsequent cycles of the lateral movement of the route bend could lead to a steady increase in the lateral resistance provided by the soil berms.

The rate of the embedment is governed by the vertical pipe load and the shear strength of the soil under the pipeline. However, it should be indicated that the pipeline-seabed contact condition for the route bend is different from the pipeline-seabed contact condition resulting from the lay process of a straight pipeline. This is for the following reasons:

Considering the soil berm during the simulation is likely to reduce the rate of lateral ratcheting of the route bend. Hence, it is conservative to ignore the berm build-up during the evaluation of the pull-out due to the tension buildup during the repeated operational start-ups and shut-downs.

In this section, the residual axial friction coefficient was employed in the simulation. It can be claimed that the peak (breakout) axial friction coefficient may not affect the lateral ratcheting behaviour of the bend, because typically the soil beneath the entire pipeline (including the bend) will not have time to reconsolidate between subsequent cool down and heat-up cycles. However, considering that reconsolidation may only take a few hours, this may be enough for the re-establishment of the peak resistance between cycles.

If peak resistance is experienced during transient temperature changes, it is well known that this can significantly modify the lateral ratcheting/pull-out behaviour of the route bend. It is recommended that sensitivity checks, using the peak (breakout) axial friction coefficient, are carried out to investigate the susceptibility of the route to lateral ratcheting/pull-out. 


\subsection{Pipeline Expansion towards SCR/PLET}

A further important consideration is whether the total pipeline expansion towards the SCR over the design life is acceptable. In other words, are the stresses on the spool located on the other end of the pipeline within limits?

As per [1], the incremental axial displacement (walking) over the design life towards the SCR should be kept within the allowable maximum limit specified by the SCR design. Pipeline anchoring will be needed if the through-life expansion towards the SCR cannot be kept within this limit.

The model presented in Figure 20 was used to investigate the rate of walking and expansion towards the SCR under the repeated start-ups and shut-downs. The results are shown in Figure 31. The figure shows that both ends (i.e. the hot end that is connected to the SCR and the cold end connected to the free end) expand towards the SCR. The rate of walking presented here is based on the static SCR tension. It can be seen that after 10 operating cycles, the total expansion towards the SCR reaches $7 \mathrm{~m}$. In this example, the allowable axial feed-in towards the SCR is assumed to be $5 \mathrm{~m}$.

Figure 13 reveals that the walking due to the SCR is in the opposite direction to the walking mechanisms of both thermal gradients and the seabed slope. The results show that the pipeline walks towards the SCR (i.e. the on-bottom SCR tension was shown to dominate the walking behaviour over the thermal transient effects and the seabed slope.)

In the scenario discussed above, a hold back anchor is required to avoid overstressing of the spool between the manifold and the PLET and also to ensure that the integrity of the SCR is not compromised.

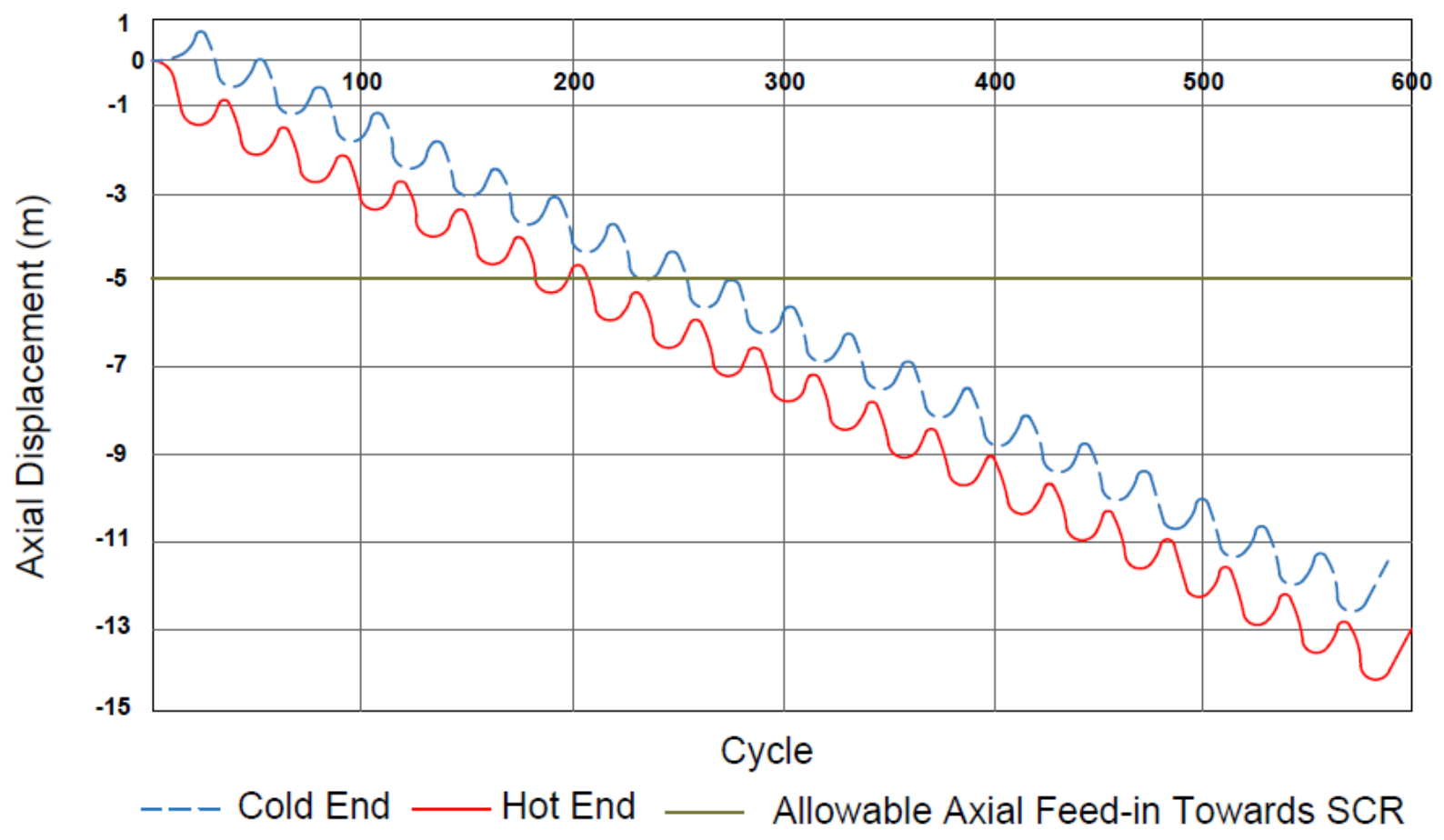

Figure 31: Total Expansion over design life

It follows from the discussion above that pipeline walking over several cycles can lead to significant global axial displacement of the pipeline, resulting in loss of SCR static tension and overstressing of the expansion 
spools / jumpers; this needs to be mitigated by anchoring. The anchor can be installed at the PLET away from the SCR transition point as per [1].

Note that using the residual value for the axial friction is conservative, since the breakout axial friction tends to reduce the rate of pipeline walking. Furthermore, the breakout axial resistance may not affect axial walking behaviour, because typically the soil beneath a pipeline will not have time to reconsolidate between subsequent shutdown and start-up cycles.

\subsection{INFLUENCE OF PIPE-SOIL INTERACTION}

Table 5 highlights the importance of the axial and lateral friction coefficient in the criteria presented in section 4.0. Sensitivity assessment should be undertaken using lower and upper bound friction values in order to determine the requirements for anchoring along a short pipeline connected to SCR.

Table 5: Influence of pipe-soil interaction

\begin{tabular}{|c|c|c|c|c|c|}
\hline Friction & Bound & $\begin{array}{l}\text { Short Pipeline } \\
\text { Slippage }\end{array}$ & $\begin{array}{l}\text { Route Bend } \\
\text { Pull-out due } \\
\text { to SCR tension } \\
\text { associated } \\
\text { with storm } \\
\text { condition }\end{array}$ & $\begin{array}{l}\text { Route bend } \\
\text { pull-out } \\
\text { associated } \\
\text { with tension } \\
\text { build-up } \\
\text { during the } \\
\text { repeated } \\
\text { operational } \\
\text { start-ups \& } \\
\text { shut-downs }\end{array}$ & $\begin{array}{l}\text { Pipeline } \\
\text { Expansion } \\
\text { towards } \\
\text { SCR/PLET }\end{array}$ \\
\hline \multirow[t]{2}{*}{$\begin{array}{l}\text { Residual Axial } \\
\text { friction } \\
\text { coefficient }\end{array}$} & Lower & $\begin{array}{l}\text { Anchor is } \\
\text { more likely }\end{array}$ & $\begin{array}{l}\text { Anchor is } \\
\text { more likely }\end{array}$ & $\begin{array}{c}\text { Less tension } \\
\text { Anchor is less } \\
\text { likely }\end{array}$ & $\begin{array}{l}\text { Anchor is } \\
\text { more likely }\end{array}$ \\
\hline & Upper & $\begin{array}{c}\text { Anchor is less } \\
\text { likely }\end{array}$ & $\begin{array}{c}\text { Anchor is less } \\
\text { likely }\end{array}$ & $\begin{array}{c}\text { More tension } \\
\text { Anchor is less } \\
\text { likely }\end{array}$ & $\begin{array}{c}\text { Anchor is less } \\
\text { likely }\end{array}$ \\
\hline \multirow{2}{*}{$\begin{array}{l}\text { Residual / } \\
\text { Breakout } \\
\text { (Peak) Lateral } \\
\text { friction } \\
\text { coefficient }\end{array}$} & Lower & No concern & $\begin{array}{l}\text { Anchor is } \\
\text { more likely }\end{array}$ & $\begin{array}{l}\text { Less stable } \\
\text { Anchor is } \\
\text { more likely }\end{array}$ & No concern \\
\hline & Upper & No concern & $\begin{array}{c}\text { Anchor is less } \\
\text { likely }\end{array}$ & $\begin{array}{c}\text { More stable } \\
\text { Anchor is less } \\
\text { likely }\end{array}$ & No concern \\
\hline $\begin{array}{l}\text { Lateral ( Berm) } \\
\text { / cyclic }\end{array}$ & Upper & No concern & $\begin{array}{c}\text { More } \\
\text { restrained } \\
\text { Anchor is less } \\
\text { likely }\end{array}$ & $\begin{array}{c}\text { More } \\
\text { restrained } \\
\text { Anchor is less } \\
\text { likely }\end{array}$ & No concern \\
\hline
\end{tabular}

Notes: 1-Orange colour indicates "Limited concern".

2- Blue colour indicates "Least concern". 


\section{3- Red colour indicates "Most concern"}

Pipe-soil interaction is essential to determine the requirements of the anchor. Therefore, it is important to ensure that sufficient soil data are available to determine the suitable pipe-soil friction coefficients before evaluating the criteria given in Table 5.

\subsection{EVALUATION OF THE ANCHORING CONCEPT}

Anchors may be required for various reasons, including pipeline initiation during laying, limiting pipeline walking and providing on-bottom tension for SCRs. Geotechnical input is needed for the design of anchors, for end termination foundations, and for connection manifolds.

There are different types of anchoring system, such as:

1. Anchor and Chain.

2. Anchor and Stab.

3. Structural anchor

4. Rock Dumping.

Table 6 is a list of the main advantages and drawbacks of each anchoring type.

Table 6: Evaluation of different anchoring system.

\begin{tabular}{|c|c|c|}
\hline $\begin{array}{c}\text { Anchoring } \\
\text { Type }\end{array}$ & Advantages & Drawbacks \\
\hline $\begin{array}{l}\text { Anchor and } \\
\text { Chain }\end{array}$ & $\begin{array}{l}\checkmark \quad \text { Can be installed before or after the } \\
\text { pipeline installation. } \\
\checkmark \quad \text { Can be installed anywhere along the } \\
\text { pipeline (i.e. pipeline ends or middle of the } \\
\text { pipeline). } \\
\checkmark \quad \text { Has got a good track record, } \\
\text { especially in the Gulf of Mexico. } \\
\checkmark \quad \text { Comprises a relatively simple design } \\
\text { when compared to other concepts such as } \\
\text { structural anchors and anchor/stab } \\
\text { concepts. } \\
\checkmark \quad \text { The anchor and chain concept is } \\
\text { relatively inexpensive. }\end{array}$ & $\begin{array}{l}x \quad \text { Size of the pile is proportional to the } \\
\text { loads experienced by the anchor. } \\
\times \quad \text { Large piles require more cautious } \\
\text { handling, installation and operation. } \\
\times \quad \text { Installing the piles after the } \\
\text { completion of the pipeline construction may } \\
\text { pose a risk on the installed pipeline } \\
\text { associated with the dropped object. }\end{array}$ \\
\hline
\end{tabular}




\begin{tabular}{|c|c|c|}
\hline $\begin{array}{c}\text { Anchoring } \\
\text { Type }\end{array}$ & Advantages & Drawbacks \\
\hline $\begin{array}{l}\text { Anchor and } \\
\text { Stab. }\end{array}$ & $\begin{array}{l}\checkmark \quad \text { Can be utilised to initiate the pipelay } \\
\text { as well as to restrain pipeline ends from } \\
\text { walking and/or expansion. }\end{array}$ & $\begin{array}{l}\text { There is insufficient track record } \\
\text { and operational data for SCR anchoring. } \\
\times \quad \text { Requires a high precision to } \\
\text { perform stab and hinge operation. } \\
\times \quad \text { May be only suitable at the pipeline } \\
\text { first end (initiation), as it requires a tight } \\
\text { installation tolerance. } \\
\times \quad \text { Piles are required to be installed } \\
\text { prior to the pipeline installation. } \\
\times \quad \text { Large piles require more cautious } \\
\text { handling, installation and operation. }\end{array}$ \\
\hline $\begin{array}{l}\text { Structural } \\
\text { anchor }\end{array}$ & $\begin{array}{l}\checkmark \quad \text { Can be used for pipeline initiation } \\
\text { during the pipeline installation. In particular, } \\
\text { a system incorporating a PLET structure and } \\
\text { piles. }\end{array}$ & $\begin{array}{l}\text { The structural anchor is required to } \\
\text { be pre-installed before the pipeline } \\
\text { installation campaign. During the pipeline } \\
\text { installation, the pipeline will be guided } \\
\text { onto the bearing arrangement via guide } \\
\text { members. Then the collars connected on } \\
\text { the pipeline are engaged with the bearing } \\
\text { arrangement. } \\
\text { x A complex design. } \\
\text { x Large piles requires more cautious } \\
\text { during the handling, installation and } \\
\text { operation. }\end{array}$ \\
\hline $\begin{array}{l}\text { Rock } \\
\text { Dumping. }\end{array}$ & $\begin{array}{l}\checkmark \quad \text { The calculations/design of the total } \\
\text { weight/volume of rock dumped per rock } \\
\text { grading and the number of passes required } \\
\text { to achieve the required cover are simple } \\
\text { when compared to other anchoring } \\
\text { concepts. }\end{array}$ & $\begin{array}{l}\text { x High cost may be associated, due to } \\
\text { the large quantities of graded rock required, } \\
\text { particularly in the locations where it is } \\
\text { difficult to source rocks. } \\
\text { x High cost may be involved with } \\
\text { mobilising a vessel suitable for rock } \\
\text { dumping in a deep-water. }\end{array}$ \\
\hline
\end{tabular}


There are several available methods to control/limit excessive axial walking. Selection of the most suitable solution is based on [1]:

1. The outcome from the walking assessments.

2. Field layout constraints.

3. Cost.

4. Constructability.

5. Adaptability to different SCR installation methods and schedules

6. Compatibility with the soil type.

The typical distribution of costs for a SCR system only is as follows (the ranges quoted being due to differences in riser diameter between 6 inch and 26 inch OD):

- Materials and Transport 30-35\%.

- Engineering and Project Management 20-10\%.

- Installation 50-55\%.

The material cost included above does not account for the following component parts:

- PLETs and anchors.

- Topside piping including pig launching and receiving facilities.

- Riser hang off structural assemblies.

The cost of the anchoring system is typically around 10-15\% of the total cost of SCR system (Materials /transport, Engineering /Project Management and installation).

\subsection{Anchor \& Chain}

An anchor and chain system utilises holdback chains attached at one end to a collar on the pipeline. The other end of the chain is connected to a pile. Figure 32 and Figure 33 shows examples for the anchor/chain concept as well as the connector clamp. 


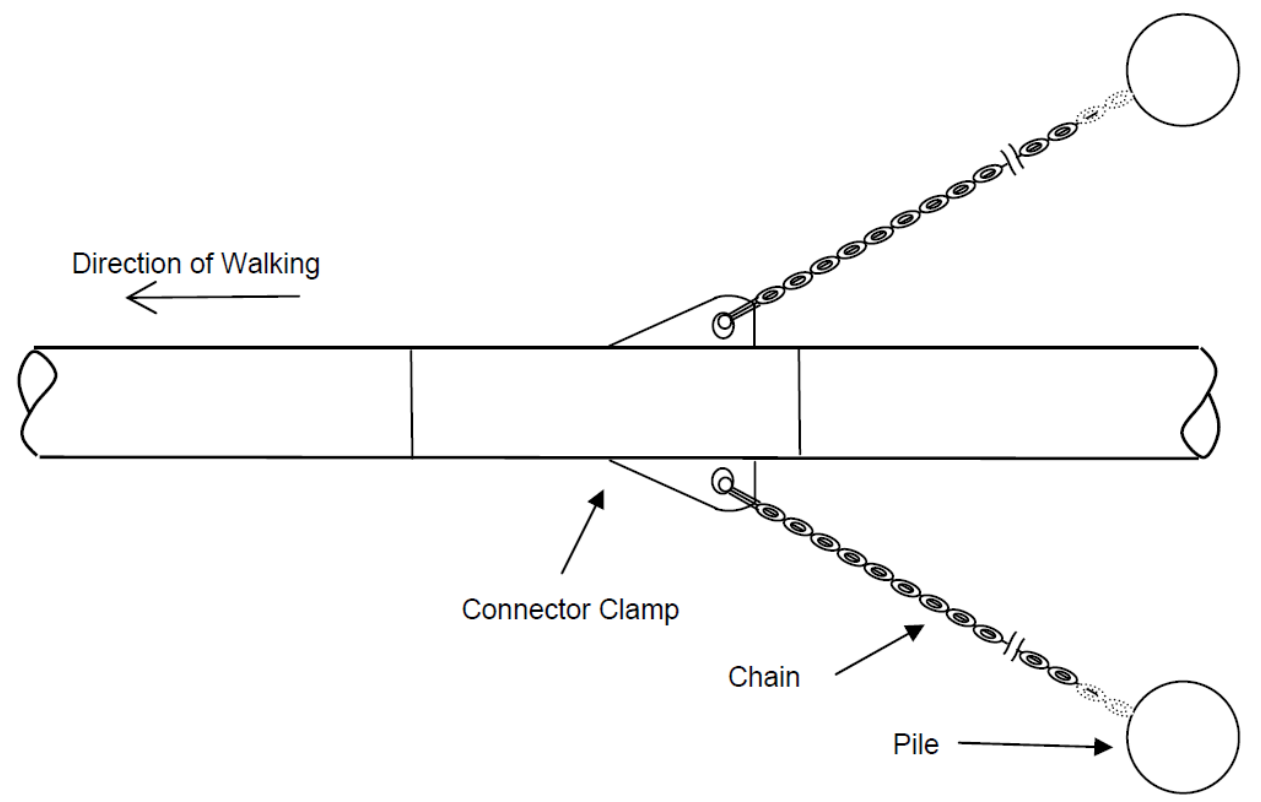

Figure 32: Dual Anchor Pile at pipeline centre / Transition point

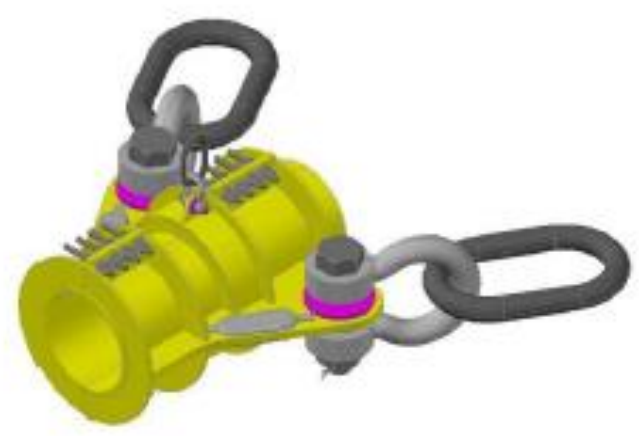

Figure 33: Connector clamp

\subsection{Anchor and Stab.}

The stab and hinge anchor system (Figure 34) can be used ( THERE IS A DIFFERENCE BETWEEN USE AND UTILISE!) to anchor a pipeline and prevent the axial feed in toward the SCR. This can be achieved by using a tee bar arrangement to provide a mechanical connection between the pipeline end and the suction pile. The tee bar arrangement provides a rigid connection of the pipeline to the piles and axially limits the pipeline from expansion/movement in both directions. 


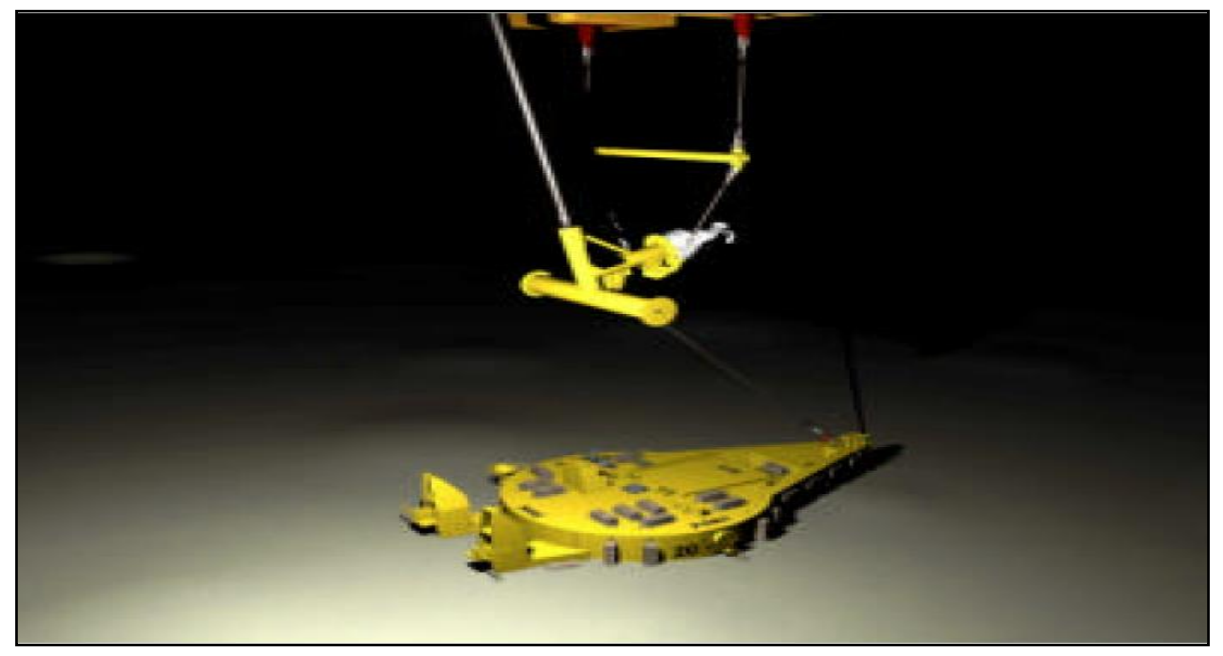

Figure 34: Anchor with Hinge and Stab [10].

\subsection{Structural anchor}

A structural anchor (as illustrated in Figure 35) used a rigid frame mounted on piles and includes a bearing arrangement to control axial feed-in of the pipeline towards the SCR.

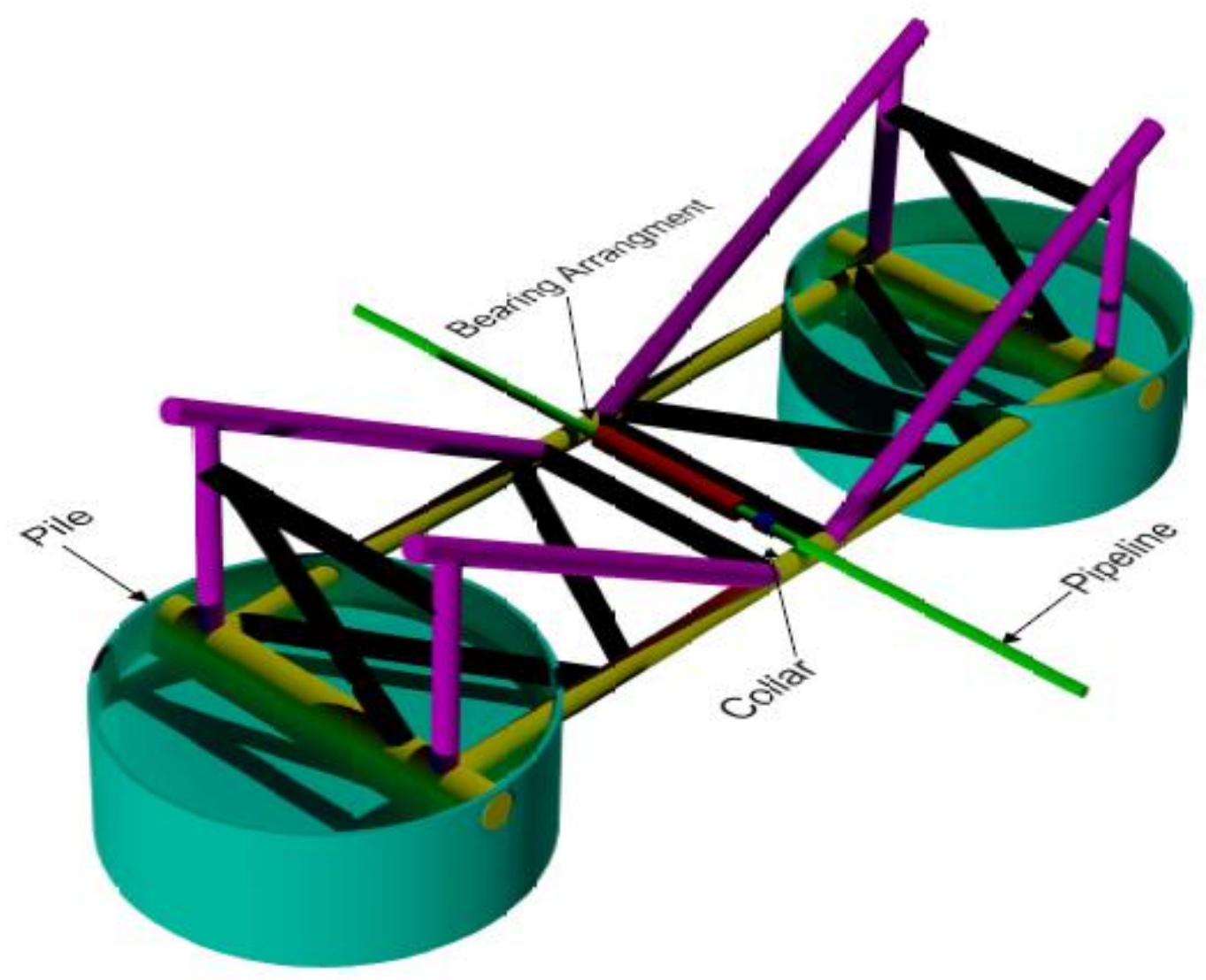

Figure 35: Structural Anchor 


\subsection{Rock Dumping}

Rock dumping (Figure 36) can be used along a pipeline in order to anchor the pipeline in the proximity of the SCR to reduce the axial feed-in towards the SCR.

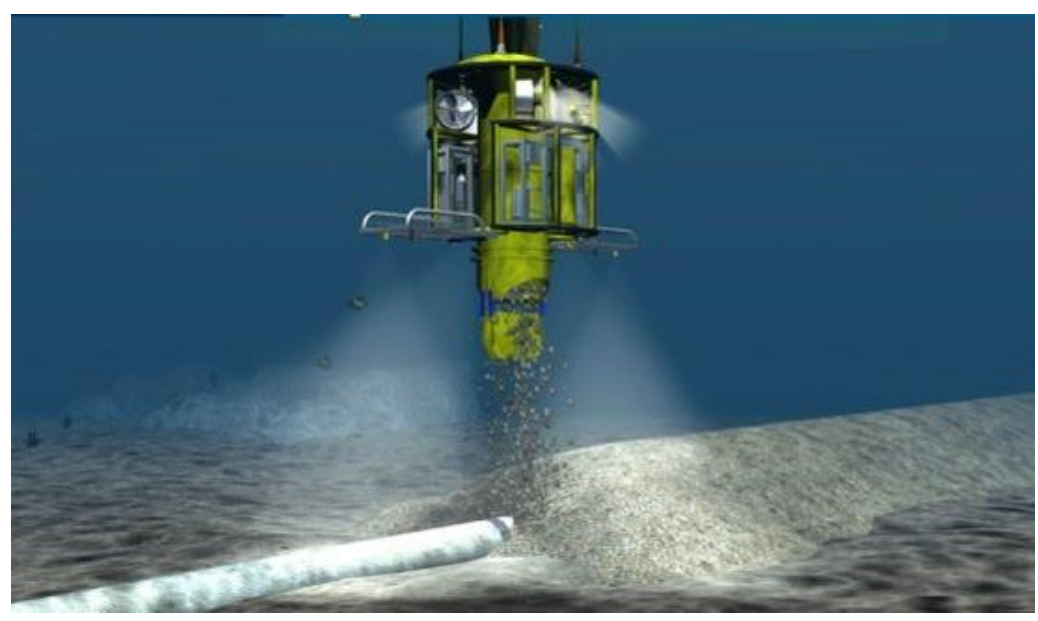

Figure 36: Rock Dumping.

\subsection{Piling}

The type of piling that (THERE IS A SIGNIFICANT DIFFERENCE BETWEEN THAT AND WHICH) can be considered for SCR anchor are as follows:

1- Suction piles

2- Driven Piles

3- Drilled and grouted Piles.

Suction piles may be used in soft clay deposits. Soft soils with sand and aggregate may require driven piles, whereas, harder seabed may require drilled and grouted piles.

Soil boring should be undertaken to assess the geotechnical characteristics of the seabed material for the piles in order to select the suitable piling system.

The pile configuration and sizing are typically based on the soil conditions and the pile capacity. There are other factors that should be accounted for during the selection of the optimum pile configuration, such as the load on the anchor that is required to prevent or reduce the axial feed-in towards the SCR or towards the PLET, constructability, complexity of the piling design and the pile's failure mode.

The piles configuration options could be as follows:

- $\quad$ Single pile, dual piles or multiple piles (cluster).

- Fixed or Free heads configurations.

Single piles are generally less complex than dual/multi-cell piles. 
Fixed head pile (Refer to Figure 37 and Figure 38): the pile head cannot rotate because it is connected to a very rigid cap. The bending moment here is non zero under lateral load applied at the pile head level. Also, in both cases the rigidity of the pile influences the degree of the rotation.

Free head pile (Refer to Figure 39, Figure $\mathbf{4 0}$ and Figure 41): the pile head can rotate freely with no restraints. This occurs when the pile head is not attached to any structure, or when the head is connected to a flexible structure that cannot prevent rotation. The bending moment at the pile head is zero unless an external moment is applied.

During assessment of the holding capacity for the pile, the effect of installation tolerances (i.e. anchor tilt and orientation) on the pile capacity should be accounted for.
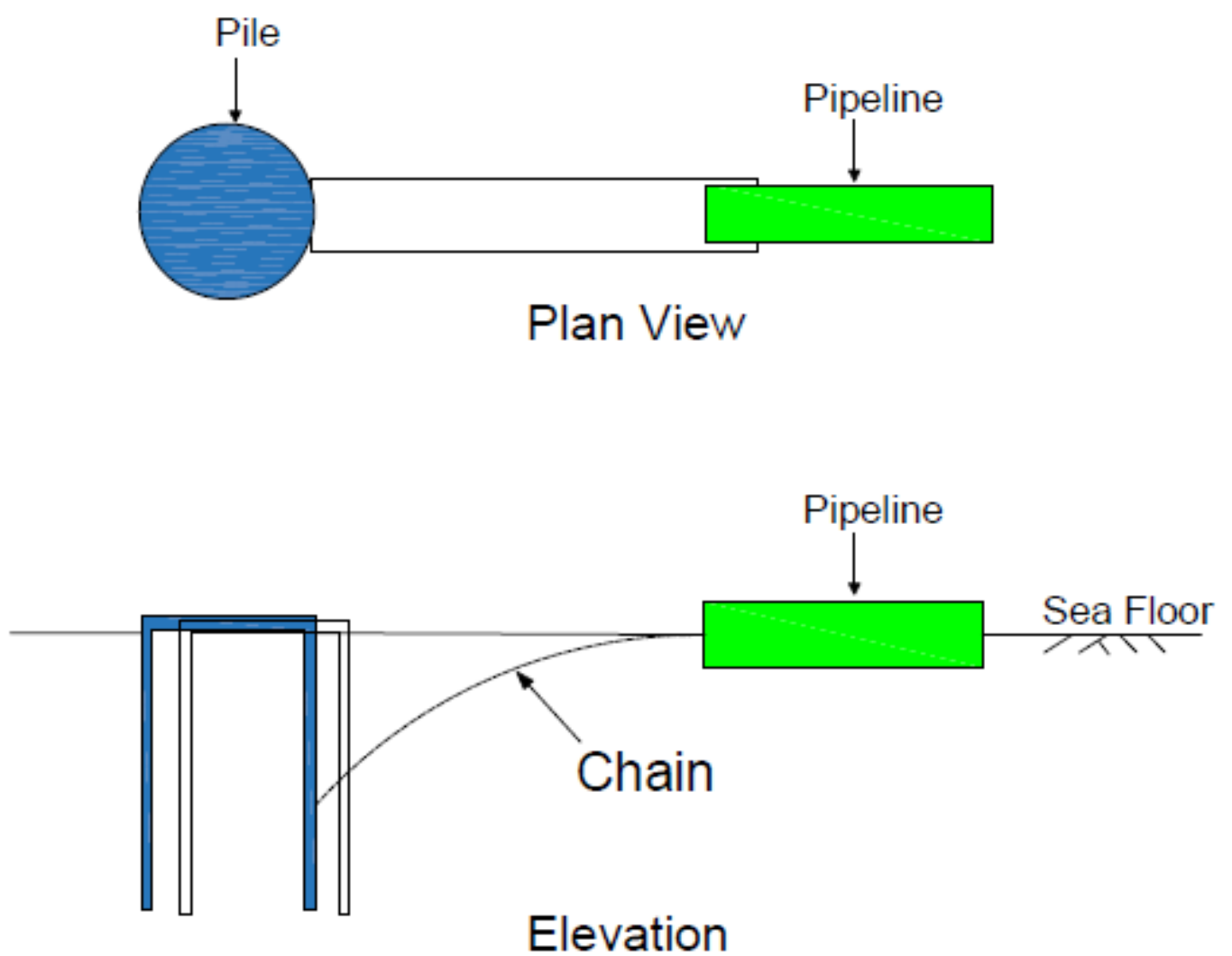

Figure 37: Fixed-Head (Single Pile) 

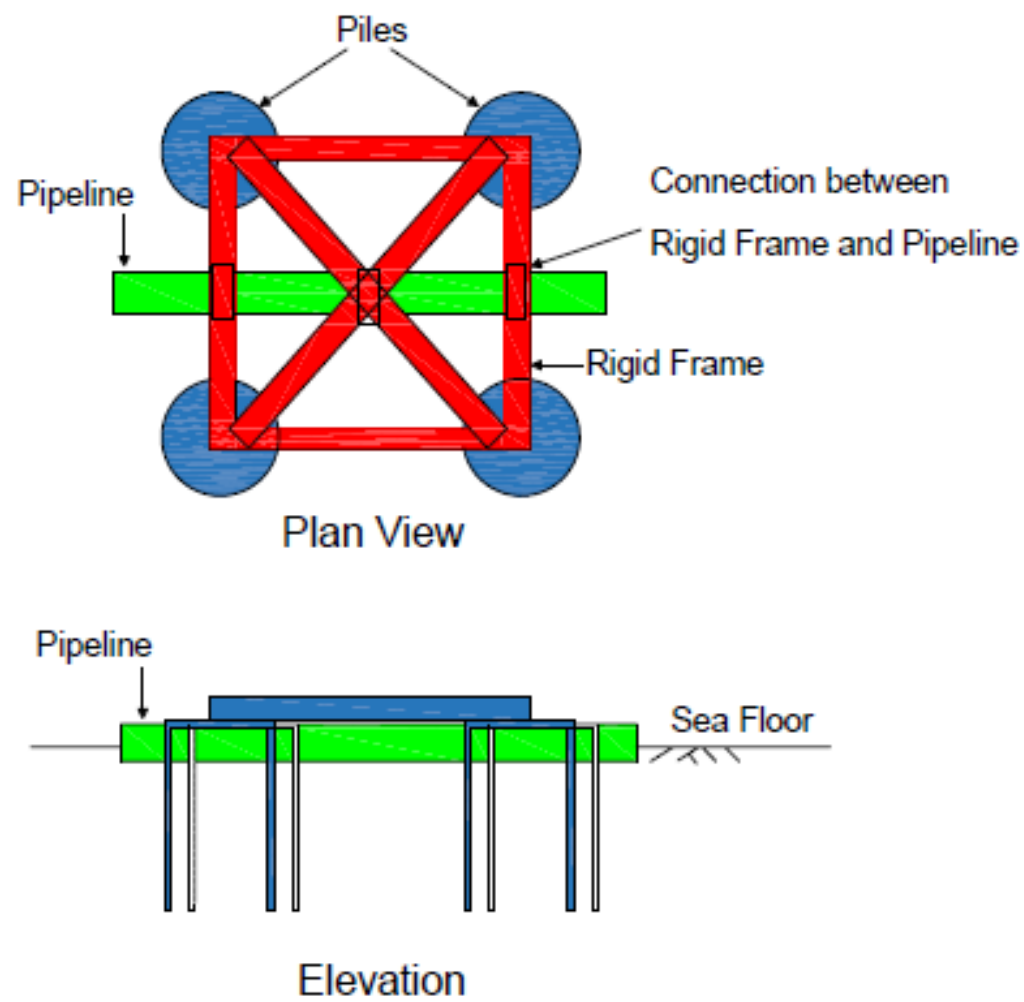

Figure 38: Fixed-Head (Cluster type) 

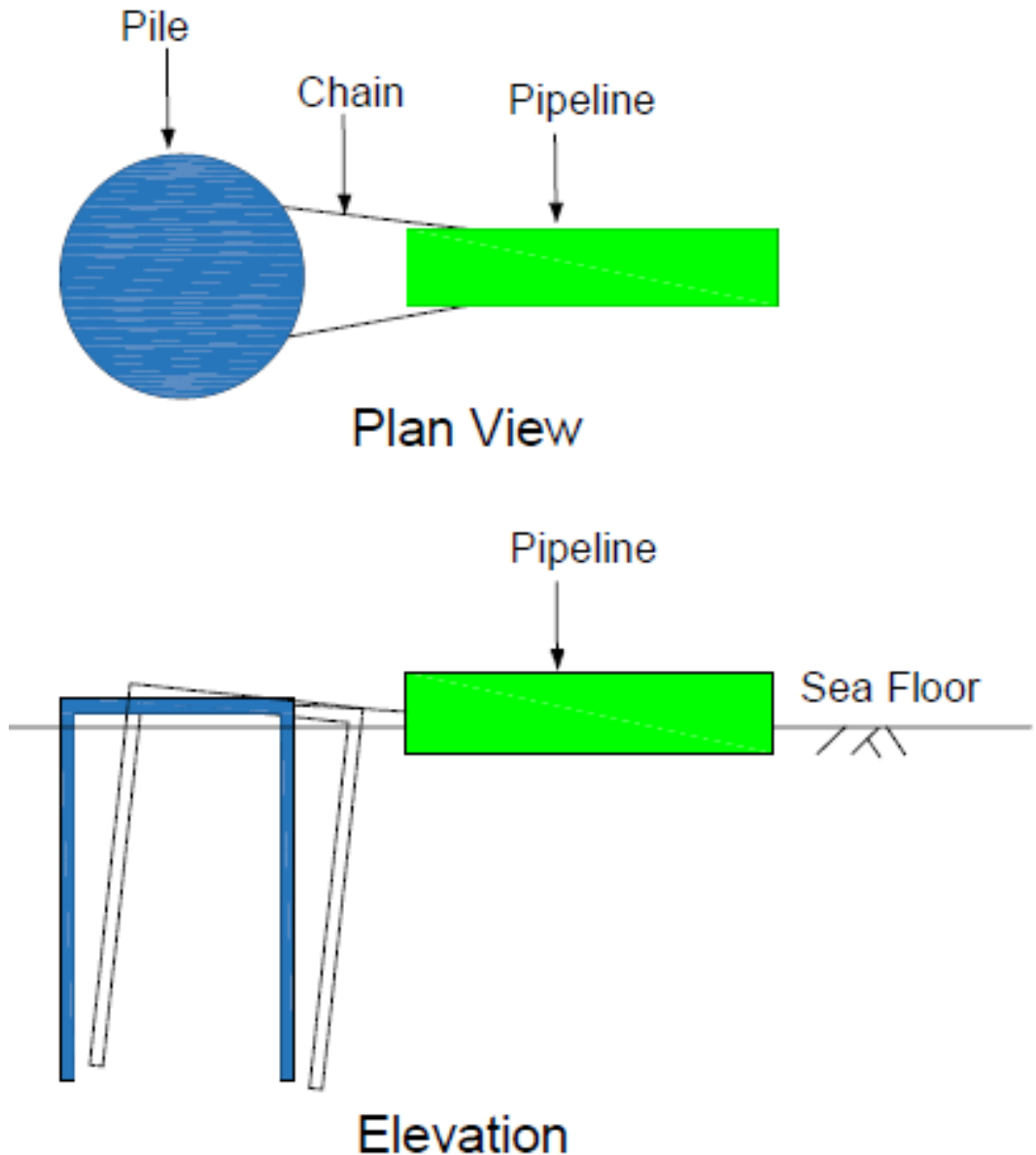

Figure 39: Free-Head (Single Pile) 


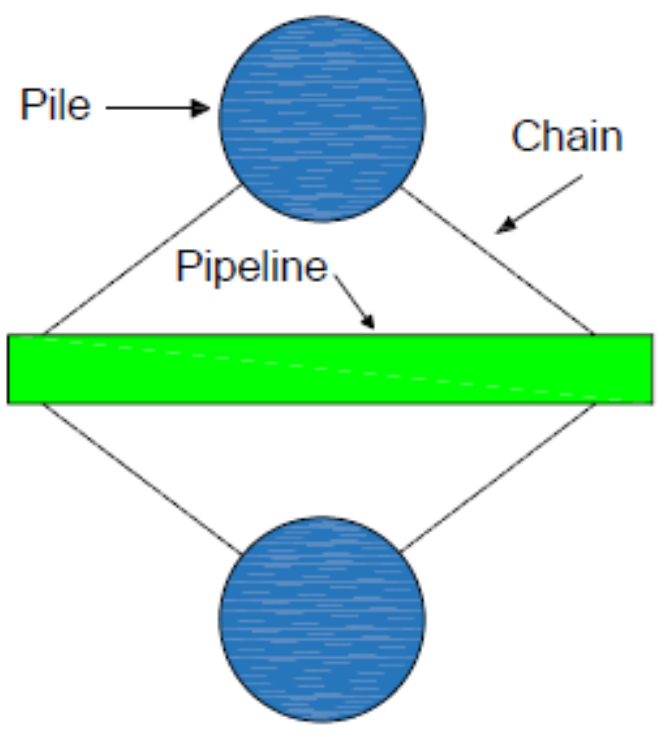

Plan View

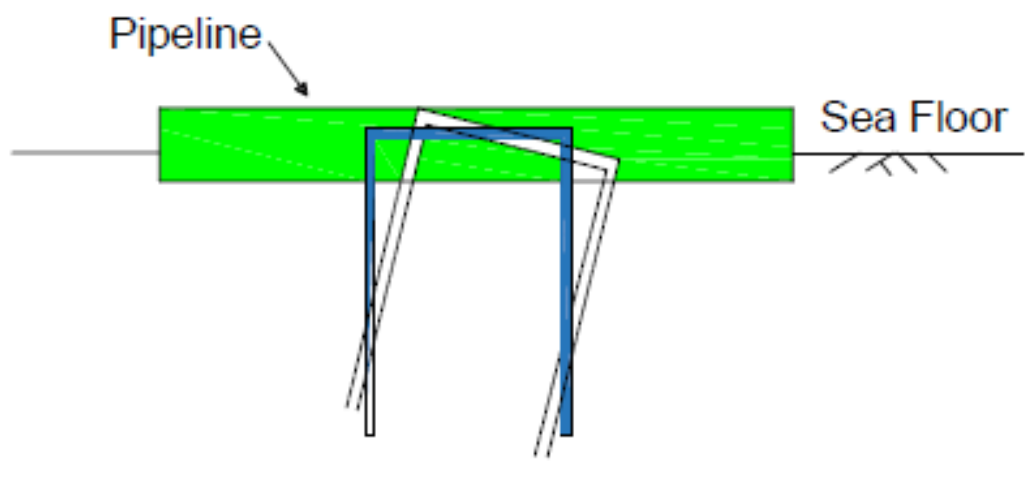

\section{Elevation}

Figure 40: Free-Head (Dual Piles) 

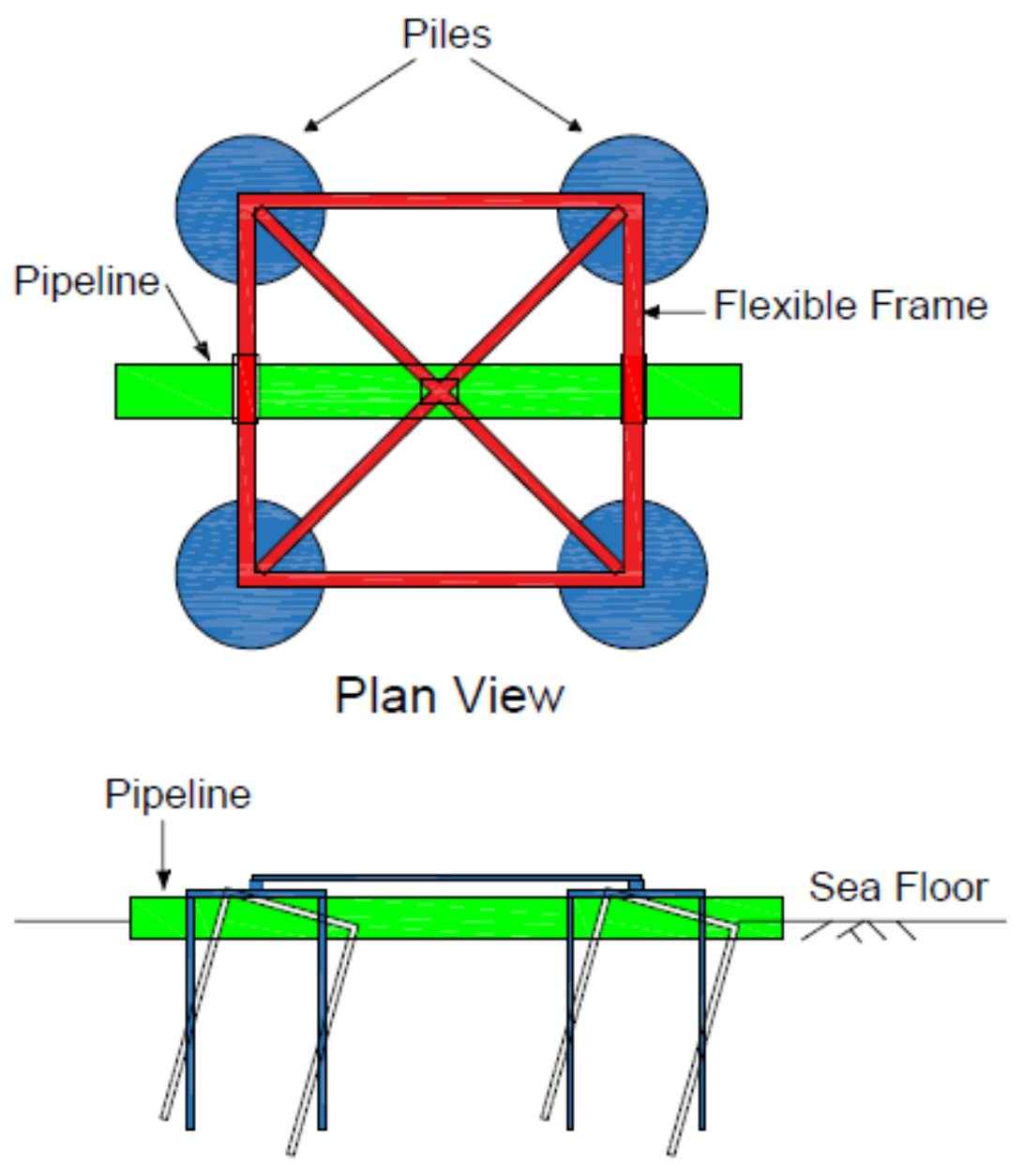

Elevation

Figure 41: Free-Head (Cluster piles) 


\section{CONCLUSIONS}

In this paper a roadmap is presented to determine requirements for anchoring a short pipeline connected to a SCR in the absence of lateral buckling.

During the development of the SCR/pipeline layouts, the following considerations should be accounted for:

- The SCR and pipeline route should provide a sufficiently long, straight run-out segment on the seabed to prevent slippage of the SCR touchdown point towards the floating production vessel. If the pipeline is not long enough and the pipeline is susceptible to slippage/pull-out towards the $\mathrm{SCR}$, then a hold-back anchor is required.

- Pipeline walking and excessive expansion towards the SCR could lead to SCR failure. Vice versa excessive SCR tension could pull the spool and consequently overstress it.

- The route bend pull-out due to the following should be avoided:

1- SCR tension associated with the storm conditions (i.e. extreme and survival load cases).

2- The repeated start-ups and shut-downs in conjunction with the SCR tension.

If the route bend pull-out can be prevented then the pipeline/SCR layout should be reconsidered by: 1) relocating the route bend, 2 ) introducing a straight pipeline section prior to the route bend, or 3 ) increasing the bend radius of the route bend. If the pipeline/SCR cannot be reconfigured, then a hold-back is required.

- The incremental axial displacement (walking), over the design life, towards the SCR should be kept within the allowable maximum axial displacement specified by the SCR design. If the through-life expansion towards the SCR cannot be kept within the limit, then pipeline anchoring is required.

The sensitivity analyses undertaken on the mobilisation distance indicated that the pipeline walking propensity increases with the small elastic mobilisation distance. Hence, it is conservative to use a small mobilisation displacement in the finite element modelling.

Pipeline slippage, lateral ratcheting/ pull-out of the route bend and pipeline walking towards the SCR can be mitigated by installing anchors at the ends of the pipeline. These anchors are typically piles attached to the pipeline (anchor and chain type) or PLET installed at the opposite side of the SCR to reduce expansion and resist pipeline walking.

The main function of the holdback anchor is to:

- $\quad$ Limit the axial feed-in (from expansion and walking) towards the SCR.

- Prevent lateral ratcheting.

Figure 42 illustrates a flowchart that can be used to determine the necessity of a hold-back anchor of a short pipeline connected to a SCR with no lateral buckling. 
Mitigation

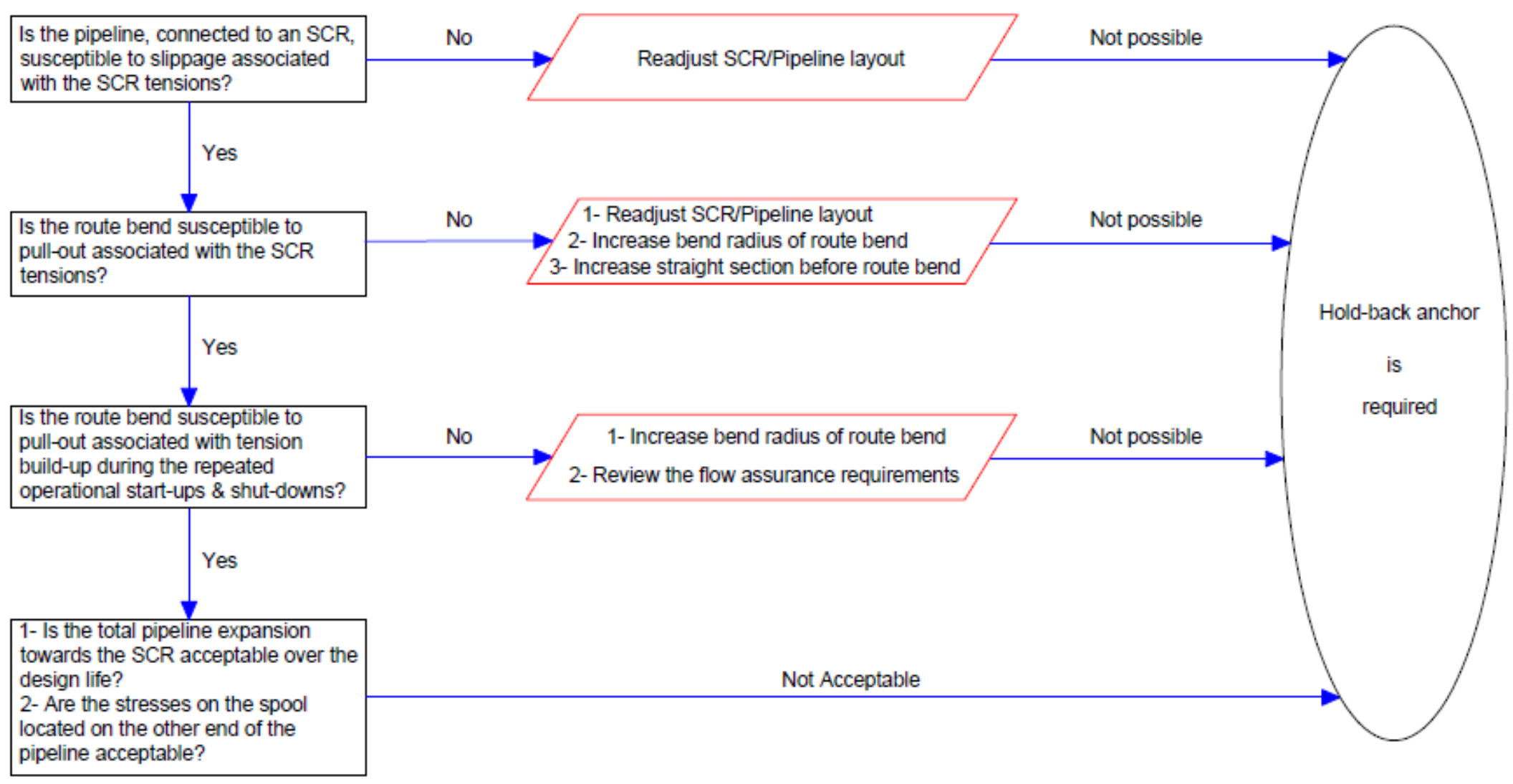




\section{REFERENCES}

1. Reda, Ahmed, Ibrahim A. Sultan, Ian M. Howard, Gareth L. Forbes, and Kristoffer K. McKee. "Pipeline walking and anchoring considerations in the presence of riser motion and inclined seabed." International Journal of Pressure Vessels and Piping 162 (2018): 71-85.

2. Reda, Ahmed, and Gareth Forbes. "Investigation into the dynamic effects of lateral buckling of high temperature/high pressure offshore pipelines." In Proceedings of Acoustics 2012Fremantle. Australian Acoustical Society, 2012.

3. Reda, Ahmed, Gareth Forbes, Kristoffer McKee, and lan Howard. "Vibration of a curved subsea pipeline due to internal slug flow." In Proceedings of the 43rd International Congress on Noise Control Engineering. Australian Acoustical Society, 2014.

4. Reda, Ahmed, Ian M. Howard, Gareth L. Forbes, Ibrahim A. Sultan, and Kristoffer K. McKee. "Design and installation of subsea cable, pipeline and umbilical crossing interfaces." Engineering Failure Analysis 81 (2017): 193-203.

5. Carr, Malcolm, David Bruton, and David Leslie. "Lateral buckling and pipeline walking, a challenge for hot pipelines." In Offshore Pipeline Technology Conference, Amsterdam, pp. 1-36. 2003.

6. Carr, Malcolm, Forbes Sinclair, and David Bruton. "Pipeline walking-understanding the field layout challenges, and analytical solutions developed for the SAFEBUCK JIP." In Offshore technology conference. Offshore Technology Conference, 2006.

7. Knouk, I. "Expansion of pipelines under cyclic operational conditions: formulation of problem and development of solution algorithm." In OMAE 1998: 17th International Conference on Offshore Mechanics and Arctic Engineering, p. 1998. 1998.

8. Bruton, David AS, Malcolm Carr, Forbes Sinclair, and lan MacRae. "Lessons learned from observing walking of pipelines with lateral buckles, including new driving mechanisms and updated analysis models." In Offshore Technology Conference. Offshore Technology Conference, 2010.

9. ABAQUS, User'S. Manual. "Version 6.12." Dassault Systemes Simulia Corp, Rhode Island, USA (2012).

10. Perinet, D., and I. Frazer. "Mitigation methods for deepwater pipeline instability induced by pressure and temperature variations." In Offshore Technology Conference. Offshore Technology Conference, 2006. 